\title{
Microarray analysis of Shigella flexneri-infected epithelial cells identifies host factors important for apoptosis inhibition
}

\author{
Christina S Faherty 1 13, D Scott Merrell11, Cristina Semino-Mora², Andre Dubois², Aishwarya V Ramaswamy ${ }^{1}$ and \\ Anthony T Maurelli*1
}

\begin{abstract}
Background: Shigella flexneri inhibits apoptosis in infected epithelial cells. In order to understand the pro-survival effects induced by the bacteria, we utilized apoptosis-specific microarrays to analyze the changes in eukaryotic gene expression in both infected and uninfected cells in the presence and absence of staurosporine, a chemical inducer of the intrinsic pathway of apoptosis. The goal of this research was to identify host factors that contribute to apoptosis inhibition in infected cells.

Results: The microarray analysis revealed distinct expression profiles in uninfected and infected cells, and these changes were altered in the presence of staurosporine. These profiles allowed us to make comparisons between the treatment groups. Compared to uninfected cells, Shigella-infected epithelial cells, both in the presence and absence of staurosporine, showed significant induced expression of JUN, several members of the inhibitor of apoptosis gene family, nuclear factor $\mathrm{kB}$ and related genes, genes involving tumor protein 53 and the retinoblastoma protein, and surprisingly, genes important for the inhibition of the extrinsic pathway of apoptosis. We confirmed the microarray results for a selection of genes using in situ hybridization analysis.

Conclusion: Infection of epithelial cells with S. flexneri induces a pro-survival state in the cell that results in apoptosis inhibition in the presence and absence of staurosporine. The bacteria may target these host factors directly while some induced genes may represent downstream effects due to the presence of the bacteria. Our results indicate that the bacteria block apoptosis at multiple checkpoints along both pathways so that even if a cell fails to prevent apoptosis at an early step, Shigella will block apoptosis at the level of caspase-3. Apoptosis inhibition is most likely vital to the survival of the bacteria in vivo. Future characterization of these host factors is required to fully understand how S. flexneri inhibits apoptosis in epithelial cells.
\end{abstract}

\section{Background}

Shigella flexneri is a Gram-negative, facultative intracellular organism, and the causative agent of bacillary dysentery. Infection with Shigella causes an intense acute inflammatory reaction that leads to the destruction of the colonic epithelium [1]. Clinical symptoms include watery diarrhea, severe abdominal pain, and bloody, mucoid stools. These symptoms of dysentery are due to the penetration of Shigella into colonic epithelial cells, which pro-

\footnotetext{
*Correspondence: amaurelli@usuhs.mil

1 Department of Microbiology and Immunology, F. Edward Hébert School of Medicine, Uniformed Services University of the Health Sciences, 4301 Jones Bridge Road, Bethesda, MD 20814, USA

Full list of author information is available at the end of the article
}

vide an intracellular environment for the bacteria to multiply and spread to adjacent cells [1]. Entry into epithelial cells is mediated by the Ipa proteins encoded on the $220-\mathrm{kb}$ virulence plasmid. Secretion of these proteins is dependent on a type III secretion system (T3SS), which is encoded by 20 genes in the mxi-spa locus of the virulence plasmid. Additional T3SS effector proteins are secreted through the T3 needle when the bacteria are inside the cytoplasm of the host cell [1].

We previously demonstrated that $S$. flexneri inhibits apoptosis in epithelial cells [2]. Apoptosis, or programmed cell death, is a form of cell death that occurs without damage or lysis to neighboring cells [3]. The 
intrinsic pathway of apoptosis is induced by various stimuli that leads to cytochrome $c$ release from the mitochondria and activation of the caspase cascade while the extrinsic pathway of apoptosis is induced by cytokine receptors of the tumor necrosis factor (TNF) family [3]. In the presence of staurosporine (STS), a chemical inducer of the intrinsic pathway of apoptosis, S. flexneri inhibits apoptosis by preventing the activation of caspase-3 despite the fact that both cytochrome $c$ release from the mitochondria and caspase-9 activation occur [2]. Given these findings, we next wanted to determine the important cellular changes that occur in epithelial cells upon infection with S. flexneri and subsequent exposure to STS. Previous research analyzed changes in eukaryotic gene expression due to $S$. flexneri invasion using whole genome arrays [4]; however, analysis in the presence of an apoptosis inducer has not performed. Therefore, the goal of this paper was to identify the changes in apoptosis-specific genes due to S. flexneri invasion both in the presence and absence of STS. This analysis will not only enhance our understanding of how S. flexneri survives inside epithelial cells, but also allow us to fully understand the mechanisms of protection from apoptosis by identifying the host factors involved in this process. The microarray analysis revealed distinct expression profiles in uninfected and infected cells, and these changes were altered in the presence of staurosporine. Based on these profiles, we made several comparisons between the treatment groups. Compared to uninfected cells, we found numerous alterations in host factors, including the jun oncogene, inhibitor of apoptosis gene family members, nuclear factor $\kappa \mathrm{B}(\mathrm{NF}-\mathrm{kB})$, and genes involving tumor protein 53 and the retinoblastoma protein, all of which are important for the pro-survival state of the infected cell. These data indicate that upon infection, the bacteria utilize multiple checkpoints along both pathways to prevent apoptosis. If Shigella fails to inhibit apoptosis at an early step, the bacteria will block apoptosis at the level of caspase- 3 . This inhibition is vital for the bacteria to survive in vivo.

\section{Results and Discussion}

The treatments for the microarray analysis were selected based on published observations that Shigella-infected HeLa cells do not undergo apoptosis in the presence of STS while uninfected HeLa cells undergo apoptosis in the same conditions [2]. The bacteria were also able to inhibit apoptosis in the colonic T84 cell line (data not shown). The temporal strategy and length of STS exposure times and infection were chosen to highlight key points in the apoptosis pathway. These key points include the activation of pro-apoptotic proteins preceding damage to the mitochondria (0.5 to 1 hour STS incubation), cytochrome $c$ release from the mitochondria (2 hour STS incubation), and activation of caspase- 3 before significant damage to the HeLa nuclei (2.75 hour STS incubation).

To phenotypically verify that these incubation times mirrored the above expectations, we exposed uninfected HeLa cells to STS for 1, 2, or 3 hours and then performed immunofluorescence analysis (Figure 1A). After 1 hour of STS treatment, cells were stained with an antibody against the Bad protein to detect total levels of the protein (Figure 1A). Phosphorylation of Bad promotes binding to 14-3-3 proteins, which prevents the pro-apoptotic function of Bad [5]. An antibody that recognizes only the phosphorylated form of Bad yielded a weak signal (data not shown). Therefore, the pro-apoptotic Bad protein was active after 1 hour of STS treatment since the dephosphorylated form of Bad was primarily detected. Next, we tested for cytochrome $c$ release from the mitochondria after 2 hours of STS treatment using a weak permeabilization treatment so only cytochrome $c$ released from the mitochondria is stained and cytochrome $c$ retained in the mitochondria produces only a weak signal [2]. The bright signal (Figure 1A) indicates that cytochrome $c$ release occurred after the 2 hours of STS treatment. Finally, caspase- 3 activation and nuclear damage was assessed after 3 hours of STS treatment using an antibody that recognizes only the activated form of caspase- 3 and the DAPI nuclear stain, respectively, as previously described [2]. Caspase-3 activation with subsequent DNA damage was detected after 3 hours of STS treatment (Figure 1A). Control experiments verified that a 2.75 hour STS incubation time was adequate for caspase-3 activation without significant DNA damage (data not shown). In addition, to highlight our previous report that S. flexneri inhibits STS-induced apoptosis, we performed the apoptosis assay with a strain of bacteria expressing a green fluorescence protein (GFP) on a low copy plasmid. After the 6 hour assay, the infected cells were fixed and stained for activated caspase- 3 . As seen in Figure $1 \mathrm{~B}$, the uninfected cell is positive for activated caspase-3; whereas the adjacent infected cell only has a bright green signal due to the GFP expression by the bacteria and lacks a signal for activated caspase-3. Control experiments showed that the bacteria expressing GFP on the low copy plasmid had the same growth rate as wildtype bacteria (data not shown).

Based on these results, we chose to examine uninfected and infected cells in the presence and absence of STS using the strategy outlined in Figure 2. The 2.5-hour incubation of Dulbecco's modified Eagle's medium (DMEM) with $50 \mu \mathrm{g} / \mathrm{ml}$ gentamicin allows the intracellular population of bacteria to grow within the HeLa cells [2]. All STS treatments were matched with treatment controls in which no STS was added. After the treatments, the RNA was harvested at the indicated times, reverse transcribed, and prepared for hybridization as 
A.

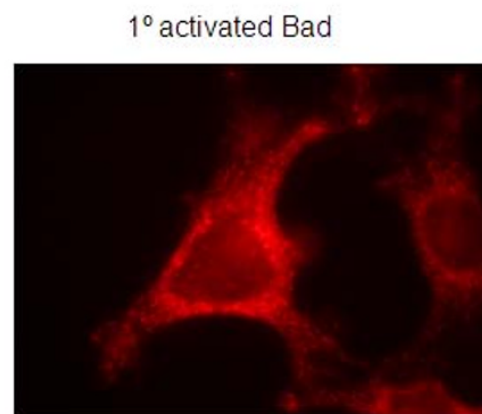

1 hour STS

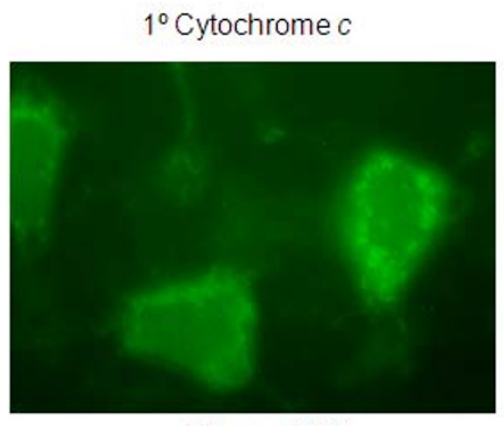

2 hours STS $1^{\circ}$ Activated Caspase- 3 and DAPI

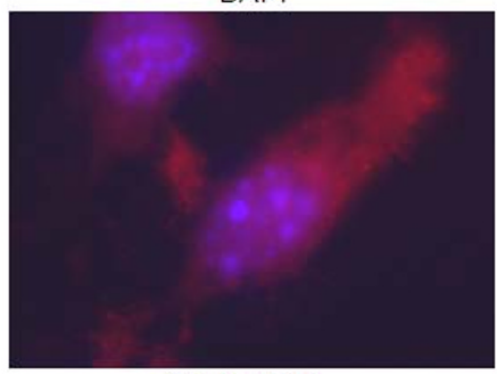

3 hours STS

B.

$1^{\circ}$ Activated Caspase- 3

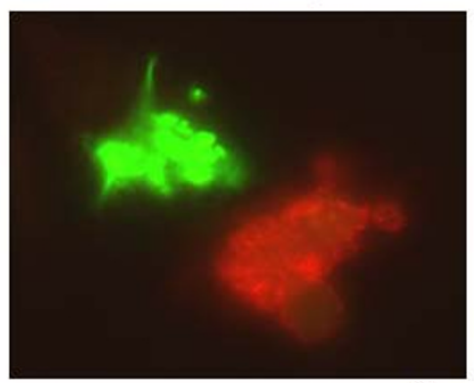

Phase Contrast

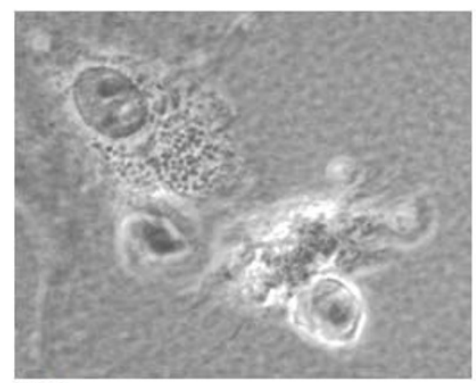

3 hours STS

Figure 1 Immunofluorescence analysis of HeLa cells treated with STS. A. Uninfected cells stained with antibodies against key points in the STSinduced apoptosis pathway, namely Bad activation at 1 hour, cytochrome $c$ release at 2 hours, and activated caspase-3 and DNA damage with DAPI nuclear staining at 3 hours STS treatment. B. A monolayer of HeLa cells was infected with Shigella harboring a low copy number plasmid expressing GFP to allow green fluorescence. Left: Merged image of the monolayer for GFP and the activated form of caspase-3. Only the uninfected cells have a positive signal for caspase-3 activation. Right: Phase contrast view to visualize the bacteria in the cytoplasm of the HeLa cell. Images are representative of three repeated experiments, and cell counts of at least 300 cells for each treatment demonstrated consistent results (data not shown).

described in the Methods. The microarrays used are specific for apoptosis genes and contain approximately 20 000 spots representing 451 genes. The resulting microarray data were collated using the Stanford Microarray Database and utilized for pairwise analysis using the Statistical Analysis for Microarrays (SAM) algorithm and the student's two-tailed t-test to identify genes showing significant changes in expression.

Additional file 1, Table S1 provides the data for all spots that showed statistically significant differences in the indicated pairwise analyses, and the complete data set is available at http://smd.stanford.edu. We performed four pairwise comparisons to identify key differences between the treatment groups, and in-depth discussion of these comparisons is provided below. The individual time points were grouped together and then utilized as a single group in the pairwise comparison. While this approach has the limitation of overlooking transient changes in host gene expression, we chose this method of analysis to identify the most consistent and significant changes since we reasoned that these changes would be vital for apoptosis inhibition during the entire six hours of infection. Additionally, due to cost limitations we chose to use one replicate of the experiment for microarray analysis and the other replicate for in situ hybridization (ISH) analysis. While this experimental design and the lack of a microarray replicate prevented statistical analysis using ANOVA, we were able to perform pairwise comparisons across variable pairs using SAM and the student's two-tailed ttest. While the analyses in the absence of a replicate are less than ideal, we compensated for this by performing extensive ISH analysis to confirm the most important changes detected in the microarray data. Additional file 2, Table S2 provides the list of genes in all comparisons categorized by function and provides brief descriptions of gene function obtained from NCBI's Entrez Gene. Cluster analysis of significantly changed genes across the treatment groups revealed that the arrays segregate into 


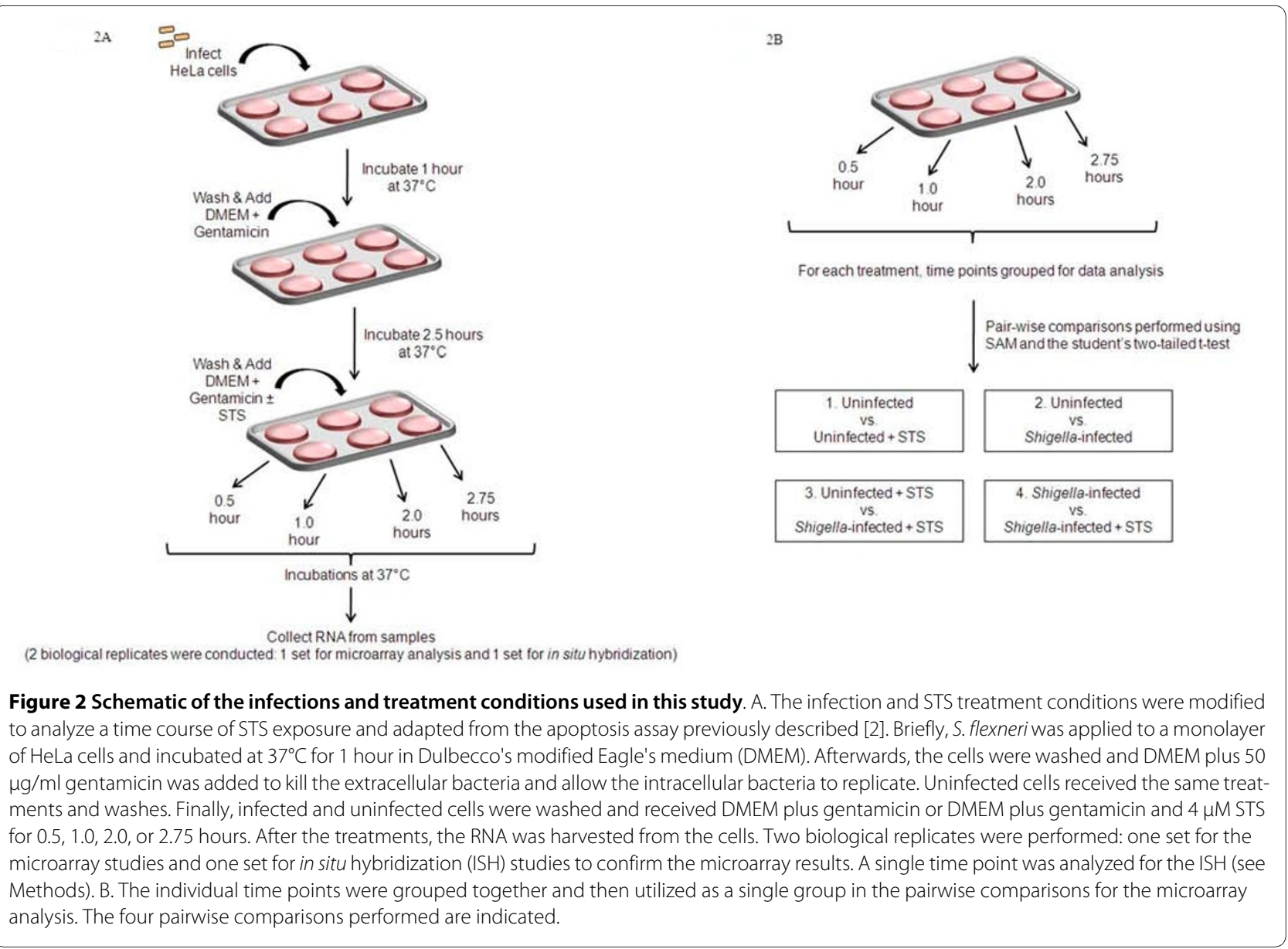

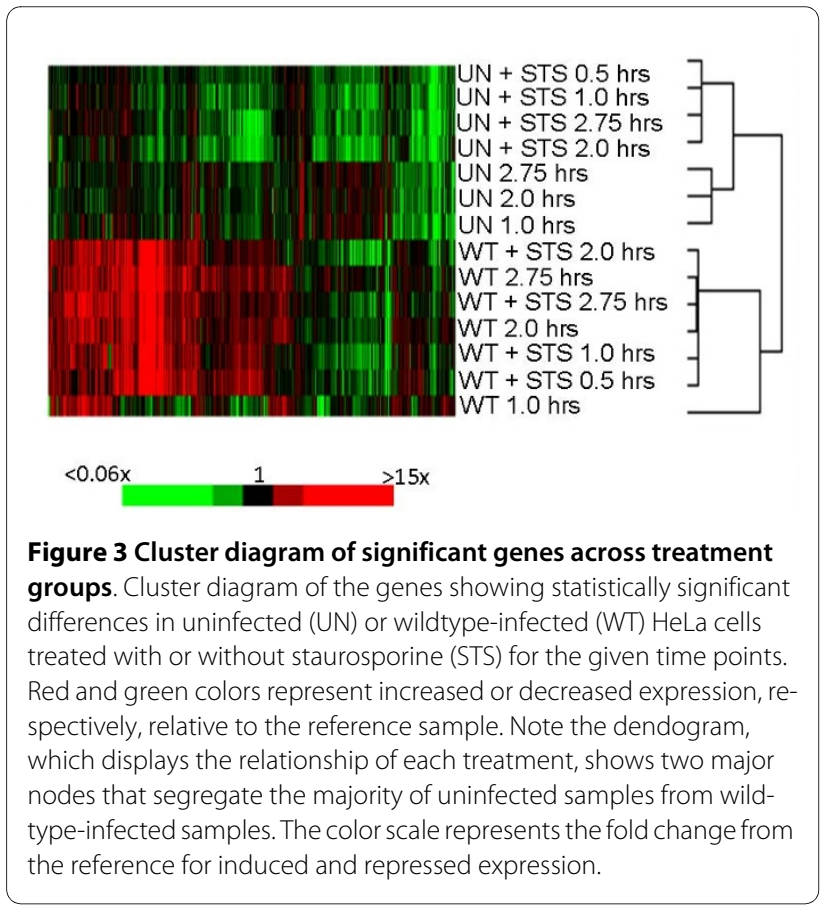

two major nodes (Figure 3). These major nodes cluster uninfected cells away from infected cells. Within the uninfected node, uninfected cells treated with STS segregate away from uninfected cells that did not receive STS treatment. However, this is not the case with infected samples; STS treated samples are interspersed with untreated samples across the node. This microarray analysis highlights clear differences in the expression of apoptotic genes in infected cells compared to uninfected cells, and interestingly, STS does not affect this pattern of apoptotic gene expression in infected cells. This analysis has provided insight into the strategies employed by $S$. flexneri to inhibit apoptosis in infected epithelial cells.

\section{Uninfected HeLa cells with STS compared to uninfected HeLa cells}

There were 122 genes whose expression was significantly altered in uninfected cells treated with STS (USTS) versus uninfected cells (U). Interestingly, all 122 genes were repressed, which indicates that the cells receiving STS treatment turned off most gene expression during apoptotic death and suggests that the pro-apoptotic proteins already available in the cell are sufficient to induce death 
without de novo synthesis. These proteins include caspases, DNA repair enzymes, p53-associated genes, proapoptotic, and pro-survival genes (Additional file 2, Table S2).

\section{Shigella-infected HeLa cells compared to uninfected HeLa cells}

The analysis identified a total of 137 induced genes and 3 repressed genes in wildtype-infected HeLa cells (WT) compared to uninfected cells (U). In general, infected cells are in a pro-survival state compared to uninfected cells due to significant induction of various genes important for apoptosis inhibition (see Figure 4). First, there was a significant induction (17-fold) of $J U N$ (also known as $c-J U N$ or $A P-1)$, which is a transcription factor and an oncogene [6]. The p38 MAPK and JNK signaling cascades induce JUN in response to pro-inflammatory cytokines and genotoxic stress. Upon activation, JNKs translocate to the nucleus to phosphorylate and enhance the transcriptional activity of JUN [7]. JUN has both pro-apoptotic and pro-survival gene targets, and it is hypothesized

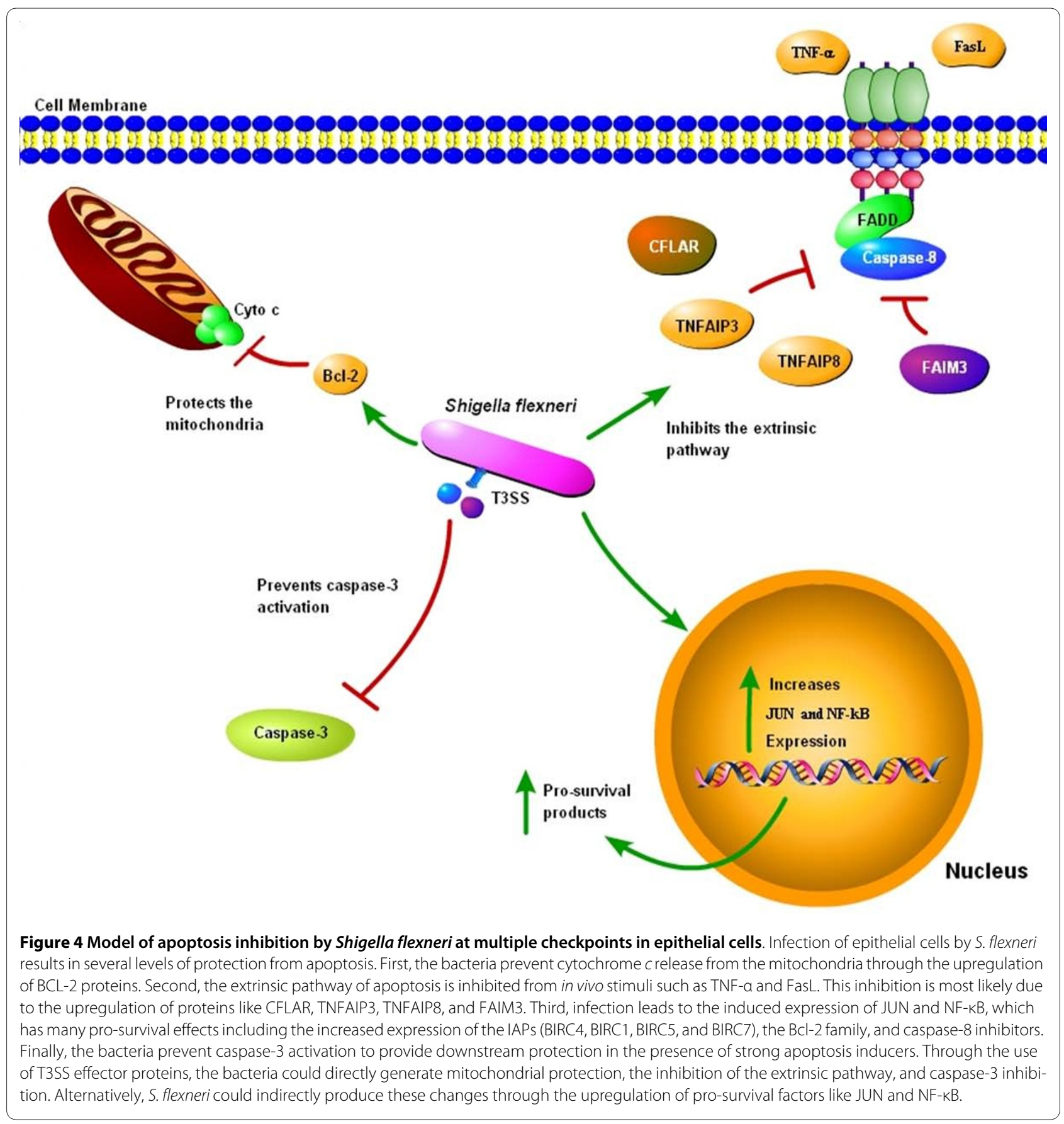


that the balance between these target genes is what determines whether the cell survives or undergoes apoptosis [7]. Lipopolysaccharides (LPS) are the major component of the outer membrane of Gram-negative bacteria, and have been shown to induce the expression of JUN $[8,9]$. It is therefore not surprising that the induction of $J U N$ is so robust in WT cells. However, we cannot rule out the possibility that a bacterial T3SS effector protein expressed intracellularly also contributes to the induction of JUN. Similar induction was also seen in a previous microarray analysis of Shigella-infected cells [4]. Below we provide evidence that WT cells are in a pro-survival state, some of which may be due to JUN induction. JUN targets include cyclins, E2F transcription factors, Ras-GRF1 (a guaninenucleotide exchange factor), and p53 [6,10-12]. Given that there is a significant increase in JUN expression, perhaps JUN is a major contributing factor to the pro-survival state of the infected cell. Future studies involving small interfering RNA (siRNA) to knock down JUN expression in infected cells will allow us to determine if $J U N$ induction upon infection is essential for the pro-survival state of the cell. Moreover, we predict that S. flexneri mutants that are unable to inhibit apoptosis may not induce JUN to the extent seen in WT cells.

Surprisingly, we found multiple upregulated genes that are responsible for inhibiting apoptosis via the extrinsic pathway (Table 1 and Figure 4). This result implies that some of the apoptotic signals that occur during infection activate the extrinsic pathway of apoptosis. Signals that activate this pathway include tumor necrosis factor- $\alpha$ (TNF- $\alpha$ ) and Fas ligand $[13,14]$. TNF- $\alpha$-induced protein 8 (TNFAIP8) was induced in infected cells and can inhibit the TNF- $\alpha$ activation of caspase-8 [15]. TNFAIP3, FAIM3, and CFLAR/c-FLIP inhibit caspase-8 activation [16-18] and all had significant induction in infected cells. Interestingly, TNFAIP3, also known as A20, was also induced in a previous microarray analysis of Shigellainfected cells [4]. Based on the array results, we examined the ability of the Shigella to inhibit the extrinsic pathway of apoptosis (Figure 5). Using TNF- $\alpha$-related apoptosis inducing ligand (TRAIL), which functions like TNF- $\alpha$ in the apoptosis assay, infected cells were able to inhibit apoptosis induction as seen upon nuclear staining. Therefore, the upregulation of genes required for the inhibition of the extrinsic pathway of apoptosis may be an important aspect for S. flexneri to inhibit apoptosis in vivo.

Other important genes induced in infected cells are members of the inhibitor of apoptosis (IAP) family. Expression of several IAP genes was significantly induced (Table 1). IAP upregulation has previously been observed in Shigella-infected cells using whole genome arrays [4]. The IAP family directly inhibits caspases [19], and caspase- 3 activation is inhibited in Shigella-infected cells in the presence of STS [2]. The IAPs may be directly involved in preventing caspase- 3 activation in infected cells treated with STS. On the other hand, if the IAP proteins are not directly involved in inhibition of caspase-3 activation in infected cells in the presence of STS, the induction of these genes could still be important to enhance the pro-survival state of the infected cell. An example is the ability of cIAP-1 to inhibit TRAF2 in TNF$\alpha$-induced apoptosis [19].

Several genes that encode proteins that associate with the mitochondrial membrane were induced in WT infected cells. For example, BCL2 was induced and is important for preventing permeabilization of the mitochondrial membrane [20]. Thus, the bacteria may utilize T3SS effector proteins to increase BCL2 expression to protect the mitochondria (Figure 4). Of note, the induction of BCL2 does not overcome the effects of STS since cytochrome $c$ release is observed in infected cells treated with STS (see below and [2]). However, STS is a strong apoptosis inducer, and the induction of BCL2 in infected cells may be sufficient to prevent cytochrome $c$ release in the absence of STS. The bacteria may encode T3SS effector proteins that target the mitochondria or pro-survival proteins, like BCL-2. These potential T3SS effectors would not be able to overcome the effects of STS, but would act as accessory proteins to enhance the pro-survival state of the cell. The increased expression of $B C L 2$ and other genes important for protecting the mitochondrial membrane may also be a result of other pro-survival effects (see below). Interestingly, BECN1 expression was also induced and BECN1 has been shown to interact with BCL-2 in viral infected cells, leading to apoptosis protection [21]. Therefore, the increased expression of BCL2 and BECN1 could promote protection of Shigellainfected cells from apoptosis.

Additional genes that were induced in infected cells include genes important for DNA replication and repair, and cell cycle progression (Additional file 2, Table S2). $X R C C 4, X R C C 5, E R C C 2, R A D 17$, and $R A D 51$, which are all key genes in DNA replication and repair [22-25], were induced. DNA damage is a signal for apoptosis [26] and maintenance of DNA integrity is an important aspect in the inhibition of apoptosis. In addition to these genes, there were also alterations in expression of genes involved in cell cycle progression or arrest in WT infected cells. One of the few repressed genes was SPATA4, which may be important for the S/G2 transition [27]. However, CUL2 and PPP2R1B were induced, and both promote cell cycle arrest [28-31]. Other genes important for cell cycle progression, including E2F3 and TFDP2, are induced $[32,33]$. As mentioned above, E2F transcription factors are regulated by JUN. The surprising changes in expression in genes that both promote and prevent cell cycle progression may reflect a complex interplay between the 
Table 1: A selection of upregulated genes in wildtype-infected cells compared to uninfected cells.

\begin{tabular}{|c|c|c|}
\hline Gene & Function & Fold Induction \\
\hline \multicolumn{3}{|c|}{ Association with the inhibition of the extrinsic pathway of apoptosis } \\
\hline TNFAIP3 & aka A20; inhibits TNF-alpha-induced apoptosis by inhibiting caspase-8 cleavage & 9.3 \\
\hline TNFRSF12A & $\begin{array}{l}\text { functions, in part, through the NF-KB pathway to up-regulate BCL-XL and BCL-W } \\
\text { expression for malignant cell survival }\end{array}$ & 5.1 \\
\hline CSE1L & $\begin{array}{l}\text { binds strongly to importin-alpha; highly expressed in tumor cell lines and may play a } \\
\text { role in inhibiting TNF-mediated cell death }\end{array}$ & 3.1 \\
\hline FAIM3 & Fas apoptotic inhibitory molecule 3 ; inhibits caspase- 8 processing & 2.7 \\
\hline BAG4 & $\begin{array}{l}\text { associates with TNFR1 and death receptor- } 3 \text { to negatively regulate downstream death } \\
\text { signaling }\end{array}$ & 2.6 \\
\hline CFLAR & $\begin{array}{l}\text { CASP8 and FADD-like apoptosis regulator; aka c-FLIP; interacts with FADD and FLICE; } \\
\text { inhibits apoptosis via human death receptors }\end{array}$ & 2.5 \\
\hline FAIM & $\begin{array}{l}\text { Fas apoptotic inhibitory molecule; pro-survival; mediates Fas resistance produced by } \\
\text { surface Ig engagement in B cells }\end{array}$ & 2.1 \\
\hline PEA15 & $\begin{array}{l}\text { a death effector domain (DED)-containing protein; inhibits both TNFRSF6 and } \\
\text { TNFRSF1A-mediated CASP8 activity \& apoptosis }\end{array}$ & 2.1 \\
\hline TNFAIP8 & tumor necrosis factor, alpha-induced protein 8 ; inhibits the activated form of caspase-8 & 2.1 \\
\hline \multicolumn{3}{|c|}{ Interaction with caspases (IAP genes) } \\
\hline BIRC4 & $\begin{array}{l}\text { aka XIAP; inhibits apoptosis through binding to TRAF1 and TRAF2; also inhibits } \\
\text { caspase- } 3 \text { and caspase-7 }\end{array}$ & 3.5 \\
\hline BIRC1 & $\begin{array}{l}\text { aka NAIP; homology to two baculoviral IAPs; suppresses apoptosis induced by various } \\
\text { signals; binds caspase-9 }\end{array}$ & 3.2 \\
\hline $\mathrm{BIRC5}$ & $\begin{array}{l}\text { aka survivin; with hepatitis } B \text { X-interacting protein (HBXIP) binds caspase-9; variant } \\
\text { DeltaEx } 3 \text { binds caspase- } 3 \text { with } B C L-2\end{array}$ & 2.8 \\
\hline BIRC7 & aka livin; shown to interact with caspase-3,-7, \& -9; degrades Smac/DIABLO & 2.8 \\
\hline
\end{tabular}

eukaryotic cell and the bacteria. A recent report demonstrated that the Shigella effector IpaB interacts with Mad2L2, leading to cell cycle arrest [34]. The authors speculate that since intestinal epithelial cells undergo rapid cell turnover, the bacteria promote cell cycle arrest to maintain infection; infected cells under cell cycle arrest resist apoptosis induction, since the cells are TUNELnegative [34]. These results validate our observations that S. flexneri inhibits apoptosis. Conversely, cell cycle arrest can lead to apoptosis especially in the absence of the retinoblastoma tumor suppressor protein (pRb) [35]. Our lab has recently reported that the $S$. flexneri effectors OspF and OspB interact with $\mathrm{pRb}$ to modulate the immune response [36]. This interaction could also protect $\mathrm{pRb}$ from degradation, which would allow cell cycle arrest without leading to apoptosis. The attempt to arrest the cell cycle and the potential protection of $\mathrm{pRb}$ enable the bacteria to exploit cell cycle arrest and prevent apoptosis at the same time.

Finally, various genes were induced that correlate with prior observations in S. flexneri infection. First, ELMO1 was induced in infected cells. The Shigella effector IpgB1 binds to ELMO1 to stimulate Rac1 activity, which induces membrane ruffling during invasion of epithelial cells. Therefore, IpgB1 acts as a molecular mimic of RhoG [37], and the induction of ELMO1 is most likely a result of the invasion process by the bacteria. Next, the $S$. flexneri effectors IpgB2 and OspB are important for nuclear factor-kappa B (NF- $\mathrm{B}$ ) activation in infected cells $[37,38]$. The genes encoding NF- $\mathrm{KB}$ and proteins required for NF$\mathrm{\kappa B}$ activation were induced in infected cells (Additional file 2, Table S2 and Figure 4), including NFKB2. NF-kB activation is important for inducing the expression of pro-survival proteins such as TNFAIP8 [15], TNFAIP3 [16], CFLAR [18], and IAPs [39,40], which are induced in infected cells as mentioned above. In addition, CARD15, also known as NOD2, was upregulated in infected cells. Nod2 recognizes muramyl dipeptide of peptidoglycan from intracellular pathogens and activates NF-кB $[41,42]$. Even more important, Nod2 is also involved in the activation of the JNK pathway [43], which can lead to JUN activation. Therefore, NF- $\mathrm{BB}$ is a significant host factor involved in inducing a pro-survival state in the infected cell. Lastly, escape from autophagy is an important aspect of $S$. flexneri infection. Atg5 binds the bacterial protein VirG/IcsA and would normally induce autophagy; how- 


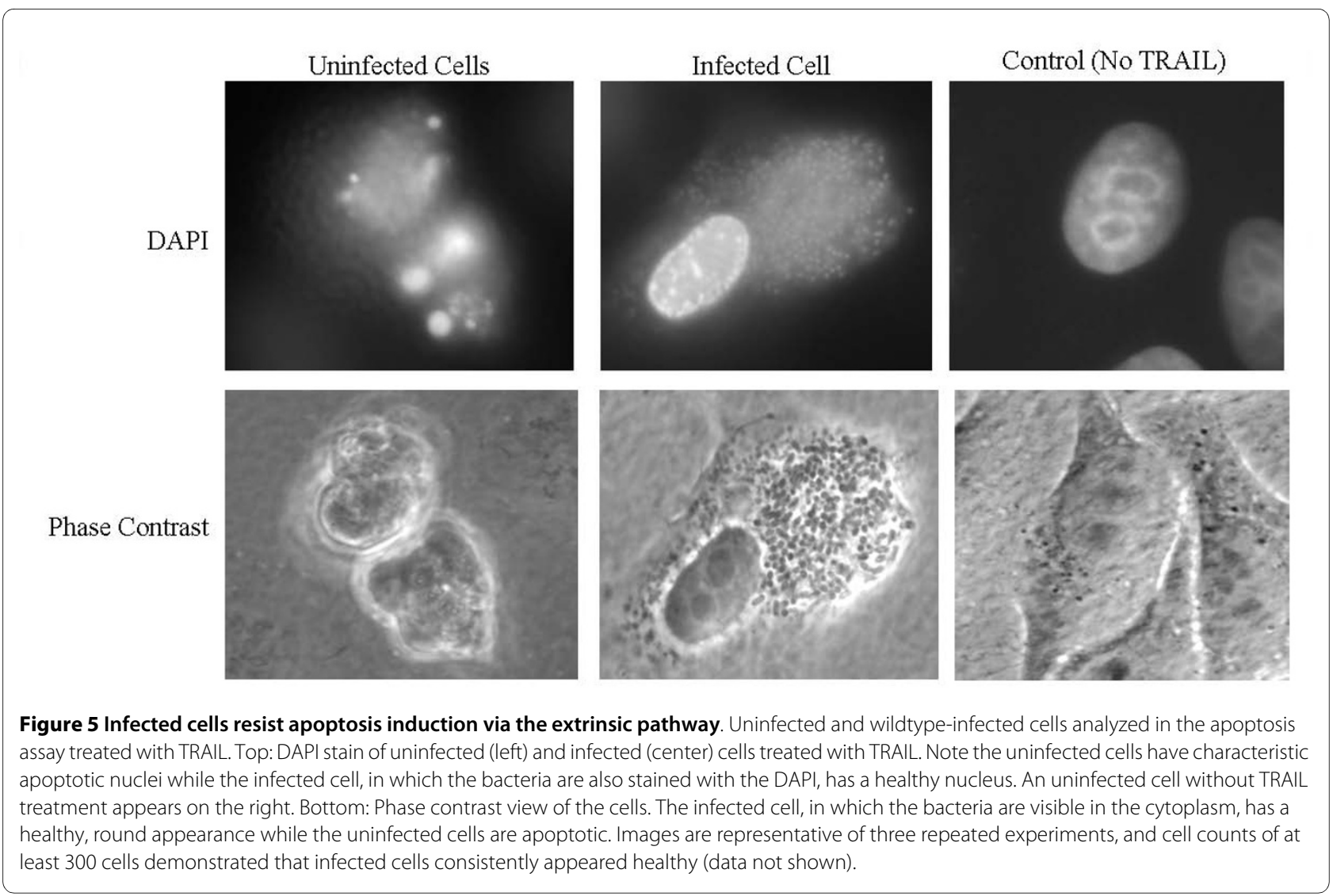

ever, the bacterial protein IcsB blocks Atg5 from binding VirG/IcsA [44]. While there was an induction of ATG12, there was no subsequent induction in ATG5 or any other gene important for autophagy. This result most likely reflects the ability of the bacteria to escape autophagy. Autophagy inhibition and apoptosis inhibition may be connected [45]. Therefore, the blockage of autophagy in infected cells is likely critical for Shigella to survive inside epithelial cells.

In summary, Shigella-infected cells are in a pro-survival state compared to uninfected cells, and a major contributing factor to this state most likely was the induction of $J U N$. Genes important for blocking the extrinsic pathway of apoptosis were also induced, in addition to the IAPs, DNA repair enzymes, and genes important for NF- $\mathrm{kB}$ activation. Moreover, the changes in gene expression seen in infected cells can be correlated to known effects of various T3SS effector proteins. The pro-survival state of infected cells may be required for apoptosis inhibition in infected cells in the presence of strong inducers like STS. At the least, the induction of these pro-survival genes may facilitate a T3SS effector protein to directly inhibit caspase- 3 activation in the presence of STS.

\section{Shigella-infected HeLa cells treated with STS compared to} uninfected HeLa cells treated with STS

There were 167 induced and 6 repressed genes in wildtype-infected cells treated with STS (WTSTS) compared to uninfected cells treated with STS (USTS). Among these, there were 72 genes that show the same differential expression, either induced or repressed, as in the $U$ versus WT comparison (Figure 6). However, some of the levels of expression do vary. For example, JUN was induced even more under WTSTS conditions; a 27-fold induction was observed. This increase in induction compared to WT cells is most likely a direct result of the addition of STS to the infected cells. Interestingly, FOSL2 or FRA-2 was induced here but not in the U versus WT comparison. FOSL2 is a part of the AP-1 transcription factor complex and has been shown to dimerize with JUN [46]. Moreover, LTBP3 was induced here but not in the U versus WT comparison. LTBP3 is important in the activation of transforming growth factor- $\beta$ (TGF- $\beta$ ) and has an AP-1 binding site in the promoter region [47]. TGF- $\beta$ can lead to cell cycle arrest, but it has also been shown to be important in tumor progression [48,49]. Thus, the increase in magnitude of $J U N$ expression seen in WTSTS could lead to the induction of FOSL2 and LTBP3 seen in these cells. 


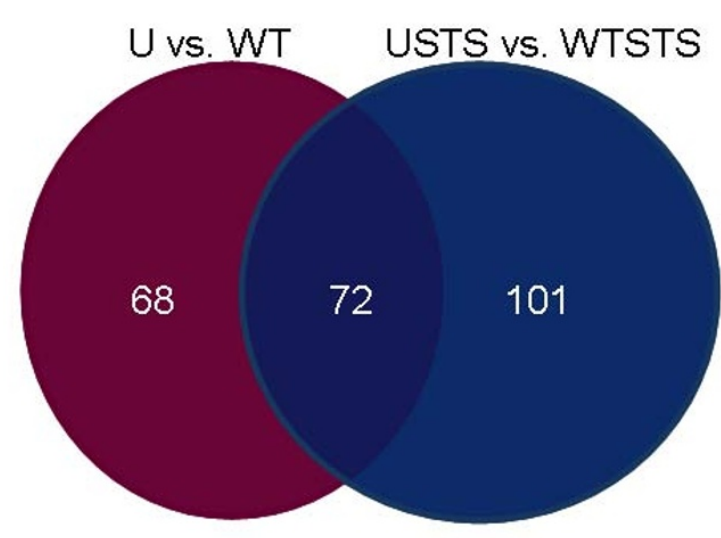

Figure 6 Venn diagram comparing Uninfected versus Wildtypeinfected to Uninfected cells treated with staurosporine versus Wildtype-infected cells treated with staurosporine. There is a total of 140 differentially expressed genes in uninfected cells $(U)$ compared to wildtype-infected cells (WT). Of those 140 genes, the same 72 genes were differentially expressed in uninfected cells treated with STS (USTS) compared to wildtype-infected cells treated with STS (WTSTS). The USTS vs. WTSTS comparison has a total of 173 differentially expressed genes.

Another example of increased expression due to the STS was seen in the induction of NFKBIA; there was approximately a 7-fold increase in WTSTS cells compared to a 3-fold increase in the $\mathrm{U}$ versus WT comparison. NFKBIA is an inhibitor of NF- $\mathrm{kB}$ since it helps to trap NF-kB in the cytoplasm [49]. The induction of NFK$B I A$ might be a response to the increased levels of NF- $\mathrm{KB}$ due to infection, or might be a direct effect of STS. However, the induction of this gene does not affect the expression of NFKB2 in WTSTS cells since NFKB2 has about the same level of expression as WT cells in the $U$ versus WT comparison.

Remarkably, approximately the same anti-apoptosis genes are induced in conditions with STS compared to the above conditions without STS suggesting the same pro-survival state of the cell was induced upon infection regardless of the presence of STS. However, there are some key differences, given the fact that the bacteria inhibit apoptosis in the presence of the strong inducer STS. The only IAP induced was BIRC2 (Additional file 2, Table S2). BIRC2 encodes cIAP1, which is involved in inhibiting caspase- 8 activation [39]. Interestingly, there was no induction of BIRC4/XIAP. Since BIRC4/XIAP inhibits caspase-3 activation [19], utilization of this IAP may not be important for the bacteria to inhibit caspase-3 activation in the presence of STS. Additionally, it is unlikely that the bacteria are using the XIAP already made without needing further significant production of the protein in the presence of STS over a three-hour time period. Therefore, we hypothesize that either the bacteria use a T3SS effector protein to directly inhibit caspase-3 activation in the presence of STS, or that the bacteria indirectly block caspase-3 activation by upregulation of other pro-survival genes. For example, genes required for NF- $\mathrm{KB}$ activation were again induced in WTSTS cells (Additional file 2, Table S2), leading to the same pro-survival effects outlined above. Interestingly, TRAF2 was induced in WTSTS, and this induction was not seen in the $U$ versus WT comparison. TRAF2 is important for caspase- 8 activation and is induced by NF- $\mathrm{KB}$ [39]. In addition, TRAF2 can activate the JNK pathway via MEKK1 leading to JUN induction [50]. Also in support of protection through NF-kB, IER3 was induced in WTSTS cells compared to USTS cells. IER3, also known as IEX$1 \mathrm{~L}$, is involved in protecting cells from TNF-induced apoptosis, and IER3 is regulated by NF-kB [51]. Additional possibilities for the inhibition of caspase- 3 in the presence of STS include the repression of pro-apoptotic pathways (see below). Once we identify the bacterial protein required for apoptosis inhibition, we can investigate how this protein functions in the eukaryotic cell.

There were two genes that appear in both sets of comparisons but show opposite directions of expression. First, NALP1 was induced in U versus WT but repressed in USTS versus WTSTS. NALP1 is part of the inflammasome in which pro-inflammatory caspase- 1 activation leads to interleukin-1 $\beta$ (IL-1 $\beta$ ) processing, especially in the presence of LPS [52]. NALP1 is suppressed by BCL-2 and $\mathrm{BCL}-\mathrm{X}_{\mathrm{L}}$ to reduce caspase- 1 activation and IL-1 $\beta$ production [53]. BCL2 was induced in WTSTS cells (see below). The Shigella effector IpaB binds and activates caspase- 1 in macrophages, leading to IL- $1 \beta$ secretion and cell death via pyroptosis [1]. There have not been any studies regarding IpaB and caspase- 1 activation in epithelial cells. While it may not be the primary method of apoptosis inhibition, NALP1 repression or inhibition of NALP1 by BCL- 2 may be an important mechanism for the pro-survival state of the infected epithelial cell in the presence of STS. This finding may be a crucial explanation for the differences in bacterial-induced cell death in macrophages and bacterial-induced cell survival in the epithelial cells. Second, EDARADD was repressed in U versus WT while it was induced in USTS versus WTSTS. EDARADD acts as an adaptor protein for EDAR to recruit TRAF2 proteins during NF-kB activation [54,55]. This induction of EDARADD possibly enhances the prosurvival effect of NF- $\mathrm{KB}$ activation in the presence of STS as described above.

The comparison between USTS to WTSTS treatments revealed numerous differences in p53-associated genes and $\mathrm{pRb}$-associated genes that were not seen in the U versus WT comparison (Table 2). p53 is a transcription factor and tumor suppressor, and can induce apoptosis by activating various targets that lead to mitochondrial per- 
Table 2: A selection of upregulated genes in wildtype-infected cells with staurosporine compared to uninfected cells with staurosporine.

\begin{tabular}{|c|c|c|}
\hline Gene & Function & Fold Induction \\
\hline \multicolumn{3}{|c|}{ Association with p53 } \\
\hline TP53BP2 & $\begin{array}{l}\text { a member of the ASPP (apoptosis-stimulating protein of p53) family of p53 } \\
\text { interacting proteins }\end{array}$ & 3.3 \\
\hline TP73L & aka tumor protein $\mathrm{p} 63$; homolog to $\mathrm{p} 53$ & 3.1 \\
\hline JUND & $\begin{array}{l}\text { member of the JUN family; a component of the AP1 TF complex; proposed to protect } \\
\text { cells from p53-dependent senescence and apoptosis }\end{array}$ & 2.8 \\
\hline P53AIP1 & $\begin{array}{l}\text { P53-regulated apoptosis-inducing protein 1; p53AIP1 regulates the mitochondrial } \\
\text { apoptotic pathway }\end{array}$ & 2.7 \\
\hline CUL4A & $\begin{array}{l}\text { functions as an E3 ligase \& with MDM2, contributes to p53 degradation; assists in } \\
\text { nucleotide excision repair in a complex with DDB }\end{array}$ & 2.6 \\
\hline LRDD & $\begin{array}{l}\text { interacts FADD \& MADD; may function as an adaptor protein in cell death-related } \\
\text { signaling processes; a p53 effector (induces apoptosis) }\end{array}$ & 2.5 \\
\hline NEDD8 & $\begin{array}{l}\text { similar to ubiquitin; conjugated to p53 via MDM2, thereby inhibiting the } \\
\text { transcriptional activity of p } 53\end{array}$ & 2.2 \\
\hline PPP2CA & $\begin{array}{l}\text { the phosphatase } 2 \text { A catalytic subunit; inhibits cell growth and activates p53 \& p21 } \\
\text { (p53-responsive); overexpression leads to G2/M arrest }\end{array}$ & 2.2 \\
\hline MDM4 & $\begin{array}{l}\text { contains a RING finger domain \& a putative nuclear localization signal; interacts with } \\
\text { p53 (stabilizes to counteract MDM2) }\end{array}$ & 2.0 \\
\hline \multicolumn{3}{|c|}{ Association with $\mathrm{pRB}$} \\
\hline RBBP4 & $\begin{array}{l}\text { involved in chromatin remodeling \& transcriptional repression associated with } \\
\text { histone deacetylation; binds directly to pRB }\end{array}$ & 3.7 \\
\hline JARID1A & $\begin{array}{l}\text { aka RBBP2; binds with pRB for tumor suppressive functions; may interact with } \\
\text { rhombotin-2 }\end{array}$ & 2.7 \\
\hline RBBP5 & $\begin{array}{l}\text { a ubiquitously expressed nuclear protein; binds pRB, which regulates cell } \\
\text { proliferation }\end{array}$ & 2.3 \\
\hline RBBP6 & $\begin{array}{l}\text { binds to unphosphorylated but not phosphorylated pRB; also binds p53; blocks } \\
\text { suppression of adenoviral E1A protein }\end{array}$ & 2.0 \\
\hline
\end{tabular}

meabilization [56,57]. p53 itself was not altered in USTS versus WTSTS, and JUN is known to be a direct repressor of p53 [7]. Therefore, the induction of JUN most likely had a significant effect on the expression of p53 in infected cells. However, TP73L or TP63, a homolog to p53 that can induce apoptosis by activating pro-apoptotic genes including $B A X, A P A F 1$, and caspase-9 [57], had increased expression in WTSTS cells. The induction of $T P 63$ most likely lead to the increased expression of $B A X$, APAF1, and caspase-9 seen in WTSTS cells. However, increased levels of these proteins and the subsequent activation of the proteins by STS had no effect on WTSTS cells since $S$. flexneri inhibits apoptosis after caspase- 9 activation [2]. Interestingly, TP63 can also induce caspase- 8 and caspase-3 [57], but these genes were not induced in WTSTS cells. Finally, many genes, in which the gene products affect p53, were upregulated. For example, TP53BP2 was induced in WTSTS cells. TP53BP2 is a part of the apoptosis-stimulating protein of p53 (ASPP) family of p53-interacting proteins and enhances 553 binding to DNA for transcriptional activation of pro-apoptotic genes [58]. Also, PPP2CA, which was induced in WTSTS cells, induces the expression of p53 and can lead to G2/M cell cycle arrest [59]. P53AIP1 was induced in WTSTS cells compared to USTS cells, and is a p53-dependent gene whose gene product binds BCL-2 to cause cytochrome $c$ release from the mitochondria [60]. Due to the mitochondrial permeabilization of Shigella-infected cells in the presence of STS, it is not surprising that these p53-regulated genes were induced. Despite the induction of p53-responsive genes, $p 53$ itself was not induced in WTSTS or in WT cells most likely due to significant JUN induction since JUN represses $\mathrm{p} 53$.

There were also induced genes in WTSTS cells that are responsible for suppressing p53 in addition to JUN. These genes include JUND [61], CUL4A [62], and NEDD8 [63] (Additional file 2, Table S2). JunD, which is in the AP-1 transcription factor complex like JUN, is also important 
for inhibiting TNF-stimulated apoptosis. JNK increases the expression of JunD, and JunD acts with NF- $\mathrm{kB}$ to increase the expression of CIAP2 [64]. GADD45 (or $G A D D 45 A$ ) which is a p53-responsive gene that recognizes damaged chromatin and facilitates topoisomerase cleavage activity to cause DNA damage [65], was induced approximately 10 -fold in WTSTS cells. In addition, GADD $45 A$ expression may be regulated by AP-1 complexes containing JunD [66]. This induction may be a result of the high induction levels of the genes associated with AP-1 complexes, namely JUN, JUND, and FOSL2. The pro-apoptotic phenotype of GADD45A does not affect WTSTS cells. Another gene that is responsible for suppressing p53 and directly degrades the protein, MDM2 [67], was induced in WTSTS cells. The induction of genes important for enhancing and suppressing p53 most likely represents an attempt by the cell to undergo apoptosis in the presence of STS, especially since p53 enhances cytochrome $c$ release from the mitochondria [56]. Conversely, the bacteria are inhibiting apoptosis and inducing a pro-survival state of the cell, which most likely explains the induced expression of genes responsible for suppressing $\mathrm{p} 53$. Interestingly, $M D M 2$ was induced in the $\mathrm{U}$ versus WT comparison in addition to the significant induction of $J U N$. The bacteria may directly upregulate MDM2 expression or the upregulation could be a response of the eukaryotic cell to the pro-survival state seen.

pRb-associated genes occur more in the USTS versus WTSTS comparison than in the $U$ versus WT comparison. The RBBP4, RBBP5/RBQ-3, RBBP6, and JARID1A or $R B B P 2$ genes were all induced in WTSTS cells and are important for $\mathrm{pRb}$ function [68-71]. In fact, $R B B P 4$ is repressed in cervical cancer due to human papillomavirus infection [69]. RBBP6 has been shown to bind $\mathrm{p} 53$, inhibit adenoviral E1A from binding $\mathrm{pRb}$, and may have a ubiquitin-like domain [72]. In addition, SERPINB2, which represses pRb pro-apoptotic signal transduction [73], was induced in WTSTS cells. As mentioned above, the bacteria may require $\mathrm{pRb}$ function to prevent apoptosis while attempting to cause cell cycle arrest. In support of this hypothesis, there were even more genes induced in the USTS versus WTSTS comparison that are involved in cell cycle arrest or progression than the genes induced in the $\mathrm{U}$ versus WT comparison. For example, CUL1, CUL3, $A P P B P 1$, and ESPL1/ESP1 are induced. These genes are important for regulation of the cell cycle [74-77]. The observations further highlight the interplay between the bacteria attempting to arrest the cell cycle while the eukaryotic cell attempts to progress the cell cycle as described above.

Finally, there were more induced genes whose gene products are localized to the mitochondria in STS conditions (Additional file 2, Table S2). For example, DIABLO and HTRA2 were induced in WTSTS cells and encode proteins responsible for inhibiting IAPs upon release from the mitochondria [78]. The pro-apoptotic $B A X$, $B C L 2 L 11, B I D, B N I P 3 L$, and $B O K$ proteins [78] were all induced in WTSTS cells as well. These pro-apoptotic genes do not affect the inhibition of caspase-3 by Shigella, especially since cytochrome $c$ release occurs in the presence of STS in infected cells [2]. Finally, the pro-survival $B C L 2 L 2$ or BCL- $W$ and GLRX2 [78,79] genes, in addition to the induction of $B C L 2$ and $C Y C S$ (encodes cytochrome c) that also occurs in WT cells, were induced in WTSTS cells. GLRX2 encodes glutaredoxin, which protects the mitochondria from oxidative stress [79]. The induction of these pro-survival genes most likely reflects an attempt of the infected cell to repair or maintain mitochondrial integrity during STS treatment of infected cells.

In summary, the changes in gene expression in the USTS versus WTSTS comparison were similar to the changes seen in the U versus WT comparison. Nevertheless, there were some key distinctions that include higher levels of induction of some genes, opposite expression of genes in the presence of STS, enhancement of the prosurvival state related to NF- $\mathrm{kB}$, induction of genes related to p53 and pRb, and the induction of more genes associated with the mitochondrial membrane. The majority of these changes most likely represent the pro-survival state induced by Shigella, and these changes were enhanced upon STS exposure. However, a few changes, including the repression of $N A L P 1$, may have a direct role in apoptosis inhibition by Shigella.

\section{Shigella-infected HeLa cells treated with STS compared to Shigella-infected HeLa cells}

The purpose of this comparison was to measure the changes in infected cells that are required for apoptosis inhibition in the presence of STS. Surprisingly, the SAM analysis revealed no significant genes. When the less stringent student's t-test was used to analyze the data, we did find changes in gene expression (Additional file 2, Table S2); however, the fold changes were not as high as the other comparisons. Approximately $80 \%$ of the changes were less than two-fold and the highest induction or repression was approximately 3 -fold. Thus, the array results demonstrated that there were few significant differences between the two conditions and suggested that the bacteria induce the same pro-survival state in infected cells regardless of the presence or absence of STS. Therefore, STS has no overall significant effect on infected cells. The cluster diagram in Figure 3 supports this hypothesis since WT cells and WTSTS cells are interspersed while U cells cluster away from USTS cells. Also in support of this hypothesis, there was no change in expression of JUN, BIRC2/CIAP1, TRAF2, or NFKB2. The absence of changes in these key genes indicates that Shi- 
gella infection itself has a pro-survival effect on the eukaryotic cell that is not altered by the presence of STS.

Of the few additional changes seen, it is interesting to see that CASP1O was repressed in WTSTS cells compared to WT cells. Caspase-10 is activated in the extrinsic pathway of apoptosis, and etoposide, a chemotherapeutic agent and cytotoxic drug, induces CASP10 expression in a p53-dependent manner [80,81]. In addition, caspase-10 is activated after cytochrome $c$ release to amplify caspase- 9 and caspase- 3 activation in the presence of etoposide. In fact, caspase-10 activation can be inhibited if cytochrome $c$ release is inhibited. More importantly, a dominant-negative form of caspase10 is able to inhibit the activation of caspase- 3 in the presence of etoposide [81]. Since S. flexneri inhibits caspase-3 activation despite cytochrome $c$ release in the presence of STS, caspase-10 could be a eukaryotic target for the bacteria to utilize to interfere with caspase-3 activation and inhibit apoptosis. Alternatively, p53 inhibition could reduce caspase-10 levels, which demonstrates the importance of the inhibition of p53 activity that occurs during infection.

Finally, it is important to note that IKBKG/NEMO was induced in the WTSTS cells compared to WT cells (Additional file 2, Table S2). NEMO is the regulatory subunit of the IKB kinase (IKK) complex that, when activated, phosphorylates the IкB proteins. Phosphorylation leads to ubiquitination of ІкB proteins, thereby releasing NF- $\kappa B$ and allowing NF- $k B$ to enter the nucleus for transcriptional activation. In addition, cIAP1 ubiquitinates NEMO in response to TNF- $\alpha$ stimulation, which is required for NF- $k B$ activation [82]. The upregulation of $N E M O$ is most likely the result of continued NF-kB activation in Shigella-infected cells in the presence of STS. Nevertheless, this comparison highlights the fact that the infected cell is under the same pro-survival state regardless of the presence or absence of STS. This strong apoptosis inducer, therefore, has little overall effect on the infected cells.

\section{In situ hybridization analysis to confirm the microarray results}

We used in situ hybridization (ISH) analysis as previously described [83] to quantify the mRNA expression of several genes and to confirm the results of the microarray analysis. ISH has been shown to be as sensitive as realtime RT-PCR [84] and is therefore an appropriate method to confirm the microarray results. Biologically independent samples were collected and analyzed with biotinlabeled probes representing genes that showed significant fold changes in the microarray results, namely $J U N$, TNFAIP3, NFKBIA, CASP10, NALP12, ERCC2, DNAJA3, and $C D 38$. As shown in Figure 7A, each probe showed the same trend for the ISH analysis as was seen in the microarray analysis, namely a significant increase in expression of each gene in cells infected with bacteria as indicated by a positive, brown staining reaction. For the $J U N$ probe, the same result was seen regardless of the presence of STS. Repressed genes also had the same trend for the ISH analysis as was seen in the microarray analysis (Figure 7B). All reactions utilized a control in which PBS was added in place of the probe. Additional controls included DNase, RNase, or DNase plus RNase treatment of the samples prior to the addition of the probes. These treatments degrade the targets in the tissue while allowing the probe to be applied to the sample, which ensures that the brown reaction does not result from nonspecific binding of the biotin-labeled probe. All controls were negative for the peroxidase reaction (data not shown). Therefore, the ISH analysis validates the microarray results reported above.

\section{Conclusion}

The identification of the Shigella proteins required for the inhibition of apoptosis and the mechanism by which the proteins inhibit apoptosis will help define which changes in eukaryotic gene expression are relevant for STS inhibition. However, the changes in eukaryotic gene expression described here appear to be important for enhancing the pro-survival state of the infected cell in the absence of a strong apoptosis inducer like STS. Future studies will define the importance of the induction of certain genes. For example, siRNA studies to knock down JUN, the IAPs, or NF- $\mathrm{kB}$ expression will help to determine which changes are required for apoptosis inhibition upon infection. In addition, analysis of the extrinsic pathway of apoptosis will allow us to determine if inhibition occurs prior to caspase- 8 or caspase- 3 activation, as well as identify which proteins in Table 1 are involved. The alterations in eukaryotic gene expression reported here are important to fully understand how Shigella inhibits apoptosis in epithelial cells.

There are other bacterial pathogens that inhibit apoptosis [85] and some of these pathogens have been utilized in similar microarray analyses to identify changes in eukaryotic gene expression in infected cells. Studies with Neisseria gonorrhoeae, which can inhibit STS-induced apoptosis at the mitochondrial level, found two to eightfold upregulation of $B F L-1, C O X-2, M C L-1$, and $C I A P 2$ in infected cells [86]. Mycobacterium tuberculosis is able to induce cell death in alveolar macrophages while it can prevent apoptosis in alveolar epithelial cells. M. tuberculosis infection of epithelial cells results in increased expression of $B C L 2$ and $p R b$, decreased expression of $B A X$ and $B A D$, and no change in $p 53$ expression despite a large increase in expression of $p 53$ in infected macrophages. In addition, the macrophages show significant inhibition of $p R b$ [87]. The $p 53$ and $p R b$ observations are 

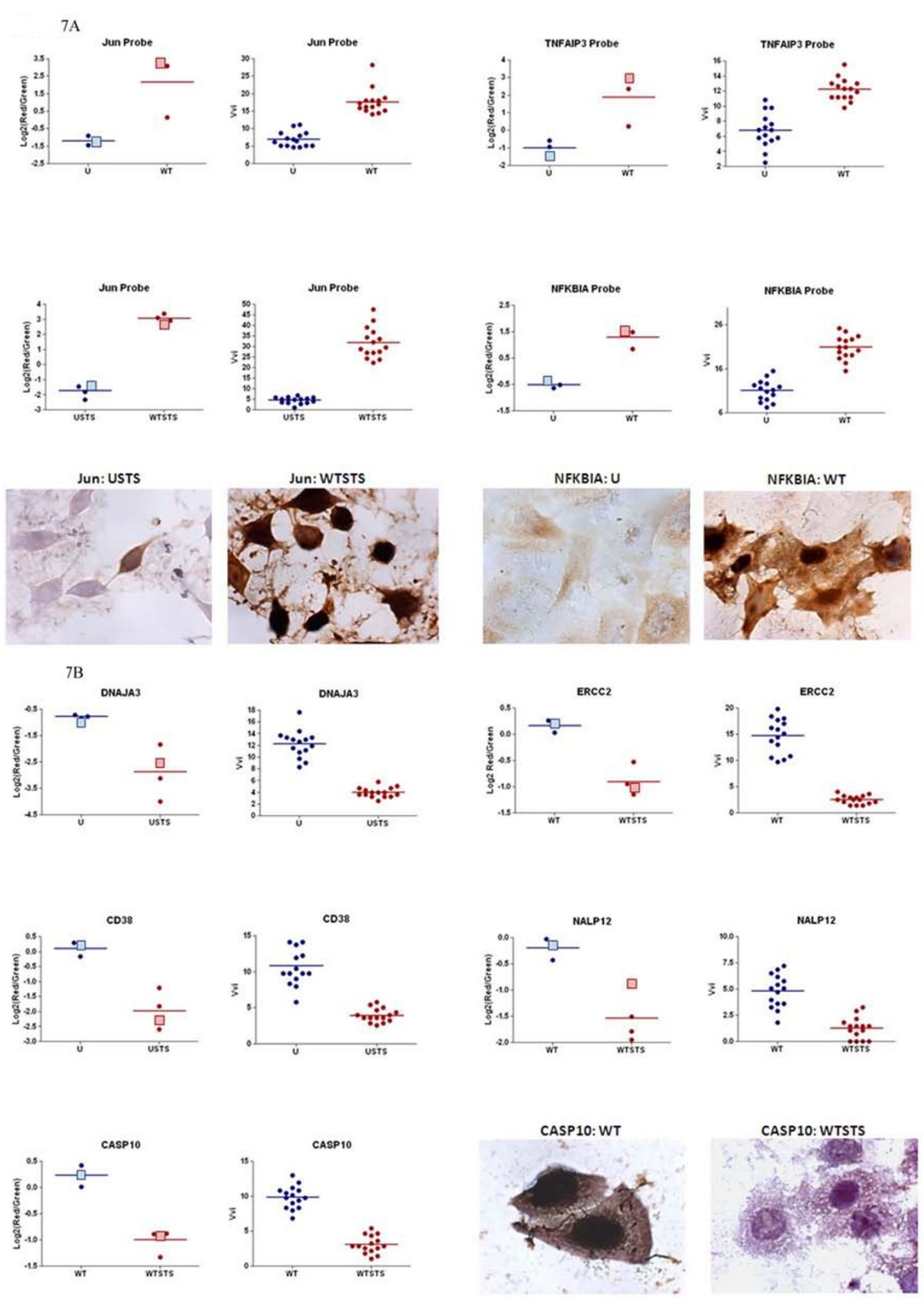

Figure 7 Comparison of the microarray and in situ hybridization results. The $\log _{2}$ of the red/green ratio for the microarray analysis is plotted on the left for the specified probe while the volumetric density (Vvi) for the in situ hybridization (ISH) analysis is plotted on the right for the specified probe. For the microarray analysis, the data for each time point of treatment (refer to Figure 2) are plotted with a line representing the mean of the data. The bigger, light-colored squares represent the time points that correlate with the ISH data. For the ISH, the Vvi for 15 fields at 400x magnification for the single time point is plotted with a line representing the mean of the data. A student's t-test was performed on the ISH data, and all p-Values were $<$ 0.0001 , indicating that there is a significant difference between uninfected cells and infected cells for the expression of each gene tested. The images represent some of the ISH reactions for the specified treatment condition and probe. Images were taken at 1000× magnification. $U=$ uninfected cells, WT $=$ infected cells, USTS = uninfected cells treated with staurosporine, and WTSTS = infected cells treated with STS. A: Induced genes. B: Repressed genes. 
similar to the changes we report in S. flexneri infection of epithelial cells, both in the presence and absence of STS. Another similarity to Shigella infection is seen with the pathogen Edwardsiella tarda, which upregulates NF- $\mathrm{kB}$ target genes, including CIAP2 and TRAF1 in macrophages [88]. Finally, analysis of Rickettsia rickettsii infected endothelial cells in the presence of STS revealed induced expression of TRAFs, many genes the products of which localize to the mitochondria, several IAPs, $A K T 1$, and $p 53$ [89]. Like the above pathogens, S. flexneri induces similar changes in eukaryotic gene expression in order to inhibit apoptosis. However, each pathogen is unique in that it may employ a different method to inhibit apoptosis. For example, while $S$. flexneri inhibits capsase3 activation, other pathogens like $N$. gonorrhoeae prevent mitochondrial permeabilization. Despite these differences, a common theme has emerged in that the bacteria induce a pro-survival state in infected cells, which results in similar changes in eukaryotic gene expression.

Knowing that $S$. flexneri inhibits STS-induced apoptosis at the level of caspase-3 activation [2] and given the changes in eukaryotic gene expression and resistance to TRAIL-induced apoptosis reported here, we propose that S. flexneri blocks apoptosis at multiple checkpoints in infected cells (Figure 4). Upon infection of epithelial cells, the bacteria either directly induce protection of the mitochondria by secreting T3SS effector proteins or indirectly protect the mitochondria by upregulating several eukaryotic genes including JUN, NFKB2, and BCL2. This possibility is supported by the evidence that there is no cytochrome $c$ release upon normal infection with Shigella [2]. Another level of protection induced upon infection is resistance to inducers of the extrinsic pathway of apoptosis, such as TRAIL. Upregulation of TNFAIP3, TNFAIP8, TNFRSF12A, FAIM3, and CFLAR are important to inhibit caspase- 8 activation, and may be direct targets of Shigella T3SS effector proteins or result from NF- $\mathrm{kB}$ activation. It is important to inhibit apoptosis from the extrinsic pathway since many in vivo stimuli are present during infection such as TNF- $\alpha$ and Fas ligand $[13,14]$. Finally, the bacteria provide downstream protection and directly inhibit caspase- 3 activation to prevent apoptosis, which is only evident when strong apoptosis inducers like STS are used. This downstream block provides protection if the invading Shigella fail to inhibit apoptosis at upstream checkpoints. While STS can overcome many of the pro-survival effects like protection of the mitochondria, the chemical cannot overcome the protection of caspase- 3 cleavage induced by the bacteria. In addition, the upregulation of genes to suppress the effects of p53 enhance the pro-survival effects of the infected cell challenged with apoptosis inducers. Future experiments will determine which bacterial T3SS effector protein(s) and which eukaryotic genes are required for S. flexneri to inhibit apoptosis. The evidence presented here clearly shows that there are multiple steps required for Shigella to successfully prevent apoptosis in infected epithelial cells. Without this protection, Shigella would not have an efficient means of survival in vivo.

\section{Methods}

\section{Bacterial strains used and growth conditions}

The strain used in the study was the wildtype $S$. flexneri serotype 2a strain $2457 \mathrm{~T}$. Bacteria were routinely cultured at $37^{\circ} \mathrm{C}$ either in Luria-Bertani broth (LB) with aeration or on tryptic soy broth plates with $1.5 \%$ agar and 0.025\% Congo red (Sigma).

\section{Immunofluorescence analysis}

After the varying STS exposures on the uninfected cells (Figure 1), cells were fixed with 3\% formaldehyde (36\% stock; Sigma) and $0.2 \%$ glutaraldehyde (25\% stock; Sigma) in $1 \times$ PBS for 5 minutes at $4^{\circ} \mathrm{C}$. Immunofluorescence analysis was performed as previously described [2]. For Bad staining, a rabbit anti-Bad antibody (Cell Signaling Technology) was used in conjunction with a goat antirabbit immunoglobulin G (IgG) antibody conjugated to Alexa-594 (Invitrogen). An additional antibody that recognizes the phosphorylated form of Bad (phospho-Bad (Ser112), Cell Signal Technology) was also used with a goat anti-mouse IgG antibody conjugated to Alexa-594 (Invitrogen). For the cytochrome $c$ release staining, the staining procedures were followed as described in the protocol provided by Molecular Probes. For the activated caspase-3 staining, a primary anti-human cleaved caspase-3 antibody (Cell Signaling Technology) was used with the same goat anti-rabbit secondary antibody above. To visualize nuclei, $5 \mathrm{mg} / \mathrm{ml}$ of 4,6-diamido- 2-phenylindole (DAPI; Molecular Probes) was diluted 1:1,000 in 1× phosphate buffered saline (PBS) and added to the monolayers for $20 \mathrm{~min}$ at room temperature in the dark. For all immunofluorescence experiments, antifade reagent (Molecular Probes) was added before coverslips were applied after the staining procedure. Samples were stored in the dark at $4^{\circ} \mathrm{C}$ and analyzed with an Olympus BX60 fluorescence microscope with an attached digital camera using $\times 100$ magnification.

\section{Apoptosis assay and RNA isolation}

The apoptosis assay was performed in HeLa cells as previously described in which infections occurred at a multiplicity of infection of 100 bacteria per HeLa cell [2] and the various treatment conditions are provided in Figure 2. In both the presence and absence of STS, 90 percent infection was achieved as previously demonstrated [2]. The STS exposure times were modified to reflect key points in the apoptosis pathway (see Results and Discussion). After the apoptosis assay, the monolayers were 
washed with $1 \times$ PBS and RNA was isolated using TRIzol reagent. RNA was extracted from the TRIzol using chloroform, precipitated using isopropyl alcohol, and cleaned using the RNeasy kit (Qiagen). DNase treatment occurred directly on the columns, and after washes, the RNA was resuspended in $30 \mu \mathrm{l}$ RNase-free water. The reference RNA for all hybridizations consisted of a pooled sample of RNA isolated from normal, healthy HeLa cells. The RNA concentration of the treatments and the reference was quantitated by determining the $\mathrm{OD}_{260}$ and the RNA integrity of all the samples was analyzed on a $1 \%$ agarose gel. All RNA was pure and not degraded by the isolation procedure (data not shown).

The apoptosis assay was modified to investigate the extrinsic pathway of apoptosis, which was also performed in HeLa cells using recombinant tumor necrosis factor- $\alpha$ related apoptosis inducing ligand (TRAIL, Calbiochem). The apoptosis assay was performed as previously described [2]. Simply, TRAIL was substituted for STS in a three-hour incubation at a concentration of $3.4 \mu \mathrm{g} / \mathrm{ml}$.

\section{Microarray hybridization and analysis}

The treatment RNA and reference RNA were concentrated to $5 \mu \mathrm{g}$ RNA in $12 \mu \mathrm{l}$ RNase-free water for cDNA synthesis. The FairPlay III kit (Stratagene) was used for preparing labeled cDNA with some modifications. 500 $\mathrm{ng} / \mu \mathrm{l}$ random hexamer solution was used in the reaction, and once the cDNA was synthesized, the treatments and reference were purified using ethanol precipitation in which the samples were placed at $-20^{\circ} \mathrm{C}$ for 1 hour. Next, the NHS-Ester containing dye coupling reaction was performed according to the protocol. The reference and treatment cDNA were subsequently indirectly labeled with Cy3 (green) and Cy5 (red) fluorophores, respectively. The samples were then purified to remove uncoupled dye, and the labeled cDNA was eluted in $50 \mu \mathrm{l}$ of 10 $\mathrm{mM}$ Tris base, $\mathrm{pH}$ 8.5. The cDNA was analyzed via a spectrophotometer to determine dye incorporation and cDNA yield. The reference sample was mixed with each of the treatments so that each treatment had $1 \mu \mathrm{g}$ of cDNA and $1 \mu \mathrm{g}$ of reference cDNA. The samples were concentrated in the speed vacuum on medium heat to 44 $\mu \mathrm{l}$, and then $11 \mu \mathrm{l}$ of $10 \times$ blocking agent $(7.5 \mu \mathrm{l} 10 \times \mathrm{Agi}-$ lent blocking reagent, $2 \mu \mathrm{l}$ human COT-1 DNA $(10 \mu \mathrm{g} /$ $\mu \mathrm{l}), 1 \mu \mathrm{l}$ poly $\mathrm{d}(\mathrm{A})_{40-60}(8 \mu \mathrm{g} / \mu \mathrm{l}), 1 \mu \mathrm{l}$ yeast tRNA $(25 \mu \mathrm{g} /$ $\mu \mathrm{l})$ ) was added to the samples. The mixtures were heated to $98^{\circ} \mathrm{C}$ for 2 minutes, cooled briefly, and the $2 \times$ hybridization buffer was added (HI-RPM, $55 \mu \mathrm{l})$, resulting in a final volume of $110 \mu \mathrm{l}$ for each sample. The samples were loaded onto the ExonHit Therapeutics microarrays (451 apoptosis-specific genes) for hybridization at $65^{\circ} \mathrm{C}$. After overnight hybridization, the arrays were washed and scanned using a 4000A scanner and the GENEPIX 3.0 software.
Data were collated using the Stanford Microarray Database [90] in which spots showing obvious abnormalities were excluded from the analysis and an uncentered metric was used during the clustering. Treatment conditions across all time points were grouped into a single condition, and each condition was then compared to the other treatment conditions to reveal changes in eukaryotic gene expression that are important for apoptosis inhibition in the presence of STS in Shigella-infected cells. This grouping allowed us to identify changes in gene expression in only those genes showing the most consistent and significant changes within each treatment group. The significance analysis of microarray (SAM) program version 2.20 and the student's t-test with a p-value cutoff of less than 0.01 were used to generate the list of significant genes. The false discovery rate (FDR) of the four pairwise comparisons did not exceed $3.1 \%$. The genes in Additional file 2, Table S2 were categorized by function and/or pathway using the gene descriptions provided by NCBI's Entrez Gene. Figure 3 was generated by average linkage clustering using the hierarchical clustering algorithm of the Cluster 2.11.0.0 program.

\section{In situ hybridization analysis}

In situ hybridization (ISH) was performed as previously described [83] with some modifications to confirm the microarray results. Infections were performed in HeLa cells with wildtype bacteria for 5.5 hours in DMEM plus $50 \mu \mathrm{g} / \mathrm{ml}$ gentamicin. When used, STS was applied at a 4 $\mu \mathrm{M}$ concentration for the last 2.5 hours of the assay. Uninfected cells received the same treatments and incubation times as infected cells in the appropriate comparisons. These time points were chosen to see the overall effect of infection and/or STS exposure on the cells. Afterwards, the HeLa cells were fixed with $3 \%$ formaldehyde (36\% stock; Sigma) and 0.2\% glutaraldehyde (25\% stock; Sigma) in $1 \times$ PBS overnight at $4^{\circ} \mathrm{C}$. For the ISH analysis, the probes and sequences used to generate the probes are listed in Table 3. The probe sequences were designed within the sequence of the corresponding microarray probe, and anneal to the cDNA sequence of the respective gene. All sequences are 32 nucleotides in length, and these sequences were analyzed with BLAST to ensure specificity to the gene target. All probes were synthesized in the Synthesis and Sequencing Facility, Biomedical Instrumentation Center, Uniformed Services University of the Health Sciences (USUHS; Bethesda, Maryland). The $5^{\prime}$ end of each oligonucleotide was labeled with biotin. After probe hybridization, avidinconjugated peroxidase and 3,3'-diaminobenzidine (DAB) tablets (Sigma) were used to detect the probes, which results in a brown reaction. Finally, the samples were counterstained with hematoxylin QS (Vector) to visualize the cells and were mounted with VectaMount. 
Table 3: Probes and sequences used for the in situ hybridization experiments.

\begin{tabular}{ll}
\hline \multicolumn{1}{c}{ Probe } & Sequence \\
\hline JUN & 5' - CCTGGGTTGAAGTTGCTGAGGTTGGGTAGAC - 3' \\
TNFAIP3 & $5^{\prime}$ - TGCGCTGGCTCGATCTCAGTTGTCTTCTGTC - 3' \\
NFKBIA & 5' - TCATGGATGATGGCCAAGTGCAGGAACGAGTC - 3' \\
CASP10 & $5^{\prime}$ - TTGCCAGGACTCCTGCGGTAAGGCTTCCAAGA - 3' \\
NALP12 & 5' - GCCACAGCTATCCAGCCACAGTTTTGGAGTC - 3' \\
ERCC2 & 5' - ATCTCTGGCACAGTTCTTGGCAGTAGATGAG - 3' \\
DNAJA3 & 5' - GGTAATGTTTGTTCCTGTGAGGCTGACACCA - 3' \\
CD38 & 5' - CGCTGGACCTGTGTGAACTGATGGGCCAGATC - 3' \\
\hline
\end{tabular}

In the data analysis, mRNA expression was quantified by a Nikon Eclipse E800 microscope as a brown reaction. Fifteen random fields were counted at $400 \times$ magnification for each preparation, according to a modification of the point-counting stereological method [91] using an intraocular reticle of 27-mm diameter, covering $3578 \mu \mathrm{m}^{2}$ (Kr409, Klarman Rulings) [83]. Volumetric density (Vvi) analysis of the different probes was performed to measure the number of intersections of the grid that fell on the positive brown reaction. Statistical significance was determined using the student's t-test to compare treatment groups.

\section{Additional material}

Additional file 1 Table S1: Data for spots that show statistically significant differences in the indicated pairwise analyses. The $\log _{2}$ red to green ratio for all spots that showed statistically significant differences in expression in the four pairwise analyses are provided.

Additional file 2 Table S2: Lists of genes in all comparisons categorized by function. On the first worksheet, there is a list of genes in all comparisons categorized by function. On the second through fifth worksheets, the list of genes from each comparison with a brief description of gene function obtained from NCBI's Entrez Gene is provided. For each comparison, induction or repression refers to the changes in gene expression in the second treatment relative to the first treatment. Each worksheet can be accessed by clicking on the tabs at the bottom of the Excel page.

\section{Authors' contributions}

CSF designed the experiments, collected the data, analyzed and interpreted the results, and drafted the manuscript. DSM assisted in the design, execution, and data analysis for the microarray experiments, and helped draft the manuscript. CS-M, AD, and AR assisted in the collection and interpretation of data for the in situ hybridization experiments. ATM assisted in the experimental design and critically revised the manuscript. All authors read and approved the final manuscript.

\section{Acknowledgements}

We would like to thank members of the Maurelli lab for their support and input, as well as Dr Hui Liu for assistance in the confirmation experiments and Michael Flora in the Bioinformatics Center for making the in situ probes. We thank the Uniformed Services University and the Henry M. Jackson Foundation for the Val Hemming Fellowship awarded to CSF. This work was supported by grant Al24656 from the National Institute of Allergy and Infectious Diseases. The opinions or assertions contained herein are the private ones of the authors and are not to be construed as official or reflecting the views of the Department of Defense or the Uniformed Services University of the Health Sciences.

\section{Author Details}

'Department of Microbiology and Immunology, F. Edward Hébert School of Medicine, Uniformed Services University of the Health Sciences, 4301 Jones Bridge Road, Bethesda, MD 20814, USA, 2Laboratory of Gastrointestinal and Liver Studies, Department of Medicine, F. Edward Hébert School of Medicine, Uniformed Services University of the Health Sciences, 4301 Jones Bridge Road, Bethesda, MD 20814, USA and ${ }^{3}$ Current address: Center for Vaccine Development, Department of Pediatrics, University of Maryland School of Medicine, Baltimore, MD 21201-1509 USA

Received: 15 July 2009 Accepted: 29 April 2010

Published: 29 April 2010

\section{References}

1. Schroeder GN, Hilbi H: Molecular pathogenesis of Shigella spp.: controlling host cell signaling, invasion, and death by type Ill secretion. Clin Microbiol Rev 2008, 21(1):134-156.

2. Clark CS, Maurelli AT: Shigella flexneri inhibits staurosporine-induced apoptosis in epithelial cells. Infect Immun 2007, 75(5):2531-2539.

3. Reed JC: Mechanisms of apoptosis. Am J Pathol 2000, 157(5):1415-1430.

4. Pedron T, Thibault C, Sansonetti PJ: The invasive phenotype of Shigella flexneri directs a distinct gene expression pattern in the human intestinal epithelial cell line Caco-2. J Biol Chem 2003, 278(36):33878-33886.

5. Zha J, Harada H, Yang E, Jockel J, Korsmeyer SJ: Serine phosphorylation of death agonist $B A D$ in response to survival factor results in binding to 14-3-3 not BCL-X(L). Cell 1996, 87(4):619-628.

6. Vogt PK: Jun, the oncoprotein. Oncogene 2001, 20(19):2365-2377.

7. Shaulian Karin: AP- 1 as a regulator of cell life and death. Nat Cell Biol 2002, 4(5):E131-136

8. Gutierrez-Venegas G, Castillo-Aleman R: Characterization of the transduction pathway involved in c-fos and c-jun expression induced by Aggregatibacter actinomycetemcomitans lipopolysaccharides in human gingival fibroblasts. Int Immunopharmacol 2008, 8(11):1513-1523.

9. Arndt PG, Suzuki N, Avdi NJ, Malcolm KC, Worthen GS: Lipopolysaccharide-induced c-Jun NH2-terminal kinase activation in human neutrophils: role of phosphatidylinositol 3-Kinase and Sykmediated pathways. J Biol Chem 2004, 279(12):10883-10891.

10. Shen Q, Uray IP, Li Y, Krisko TI, Strecker TE, Kim HT, Brown PH: The AP-1 transcription factor regulates breast cancer cell growth via cyclins and E2F factors. Oncogene 2008, 27(3):366-377.

11. Katabami M, Donninger H, Hommura F, Leaner VD, Kinoshita I, Chick JF, Birrer MJ: Cyclin A is a c-Jun target gene and is necessary for c-Juninduced anchorage-independent growth in RAT1a cells. $\mathrm{J}$ Biol Chem 2005, 280(17):16728-16738.

12. Leaner VD, Donninger $H$, Ellis CA, Clark GJ, Birrer MJ: p75-Ras-GRF1 is a cJun/AP-1 target protein: its up regulation results in increased Ras activity and is necessary for c-Jun-induced nonadherent growth of Rat1 a cells. Mol Cell Biol 2005, 25(8):3324-3337.

13. Jung HC, Eckmann L, Yang SK, Panja A, Fierer J, Morzycka-Wroblewska E, Kagnoff MF: A distinct array of proinflammatory cytokines is expressed in human colon epithelial cells in response to bacterial invasion. $J$ Clin Invest 1995, 95(1):55-65.

14. Mizuta M, Nakajima H, Mizuta N, Kitamura Y, Nakajima Y, Hashimoto S, Matsuyama H, Shime N, Amaya F, Koh H, et al.: Fas ligand released by activated monocytes causes apoptosis of lung epithelial cells in human acute lung injury model in vitro. Biol Pharm Bull 2008, 31(3):386-390.

15. You Z, Ouyang H, Lopatin D, Polver PJ, Wang CY: Nuclear factor-kappa Binducible death effector domain-containing protein suppresses tumor necrosis factor-mediated apoptosis by inhibiting caspase-8 activity. $J$ Biol Chem 2001, 276(28):26398-26404.

16. He KL, Ting AT: A20 inhibits tumor necrosis factor (TNF) alpha-induced apoptosis by disrupting recruitment of TRADD and RIP to the TNF receptor 1 complex in Jurkat T cells. Mol Cell Biol 2002, 22(17):6034-6045. 
17. Hitoshi Y, Lorens J, Kitada SI, Fisher J, LaBarge M, Ring HZ, Francke U, Reed JC, Kinoshita S, Nolan GP: Toso, a cell surface, specific regulator of Fasinduced apoptosis in T cells. Immunity 1998, 8(4):461-471.

18. Micheau O, Lens S, Gaide O, Alevizopoulos K, Tschopp J: NF-kappaB signals induce the expression of c-FLIP. Mol Cell Biol 2001 21(16):5299-5305

19. Mace PD, Shirley S, Day CL: Assembling the building blocks: structure and function of inhibitor of apoptosis proteins. Cell Death Differ 2010, 17(1):46-53.

20. Cory S, Adams JM: The Bcl2 family: regulators of the cellular life-ordeath switch. Nat Rev Cancer 2002, 2(9):647-656

21. Liang $X H$, Kleeman $L K$, Jiang HH, Gordon G, Goldman JE, Berry G, Herman $B$, Levine B: Protection against fatal Sindbis virus encephalitis by beclin, a novel Bcl-2-interacting protein. J Virol 1998, 72(11):8586-8596.

22. Thacker J, Zdzienicka MZ: The mammalian XRCC genes: their roles in DNA repair and genetic stability. DNA Repair (Amst) 2003, 2(6):655-672.

23. Reardon JT, Ge H, Gibbs E, Sancar A, Hurwitz J, Pan ZQ: Isolation and characterization of two human transcription factor IIH (TFIIH)-related complexes: ERCC2/CAK and TFIIH. Proc Natl Acad Sci USA 1996, 93(13):6482-6487

24. Post SM, Tomkinson AE, Lee EY: The human checkpoint Rad protein Rad17 is chromatin-associated throughout the cell cycle, localizes to DNA replication sites, and interacts with DNA polymerase epsilon. Nucleic Acids Res 2003, 31(19):5568-5575.

25. Kim PM, Allen C, Wagener BM, Shen Z, Nickoloff JA: Overexpression of human RAD51 and RAD52 reduces double-strand break-induced homologous recombination in mammalian cells. Nucleic Acids Res 2001, 29(21):4352-4360.

26. Roos WP, Kaina B: DNA damage-induced cell death by apoptosis. Trends Mol Med 2006, 12(9):440-450.

27. Liu SF, Lu GX, Liu G, Xing XW, Li LY, Wang Z: Cloning of a full-length cDNA of human testis-specific spermatogenic cell apoptosis inhibitor TSARG2 as a candidate oncogene. Biochem Biophys Res Commun 2004, 319(1):32-40

28. Kipreos ET, Lander LE, Wing JP, He WW, Hedgecock EM: cul-1 is required for cell cycle exit in C. elegans and identifies a novel gene family. Cell 1996, 85(6):829-839

29. Huh K, Zhou X, Hayakawa H, Cho JY, Libermann TA, Jin J, Harper JW, Munger K: Human papillomavirus type 16 E7 oncoprotein associates with the cullin 2 ubiquitin ligase complex, which contributes to degradation of the retinoblastoma tumor suppressor. J Virol 2007, 81(18):9737-9747.

30. Li H, Zhao LL, Funder JW, Liu JP: Protein phosphatase 2A inhibits nuclear telomerase activity in human breast cancer cells. J Biol Chem 1997, 272(27):16729-16732.

31. Lee TH, Solomon MJ, Mumby MC, Kirschner MW: INH, a negative regulator of MPF, is a form of protein phosphatase 2A. Cell 1991, 64(2):415-423.

32. Olsson AY, Feber A, Edwards S, Te Poele R, Giddings I, Merson S, Cooper CS: Role of E2F3 expression in modulating cellular proliferation rate in human bladder and prostate cancer cells. Oncogene 2007, 26(7):1028-1037.

33. Zhang Y, Chellappan SP: Cloning and characterization of human DP2, a novel dimerization partner of E2F. Oncogene 1995, 10(11):2085-2093.

34. Iwai H, Kim M, Yoshikawa Y, Ashida H, Ogawa M, Fujita Y, Muller D, Kirikae T, Jackson PK, Kotani S, et al:: A bacterial effector targets Mad2L2, an APC inhibitor, to modulate host cell cycling. Cell 2007, 130(4):611-623.

35. Wang JY, Naderi S, Chen TT: Role of retinoblastoma tumor suppressor protein in DNA damage response. Acta Oncol 2001, 40(6):689-695.

36. Zurawski DV, Mumy KL, Faherty CS, McCormick BA, Maurelli AT: Shigella flexneri type III secretion system effectors OspB and OspF target the nucleus to downregulate the host inflammatory response via interactions with retinoblastoma protein. Mol Microbiol 2009, 71(2):350-368

37. Handa Y, Suzuki M, Ohya K, Iwai H, Ishijima N, Koleske AJ, Fukui Y, Sasakawa C: Shigella IpgB1 promotes bacterial entry through the ELMO-Dock180 machinery. Nat Cell Biol 2007, 9(1):121-128.

38. Fukazawa A, Alonso C, Kurachi K, Gupta S, Lesser CF, McCormick BA Reinecker HC: GEF-H1 mediated control of NOD1 dependent NFkappaB activation by Shigella effectors. PLoS Pathog 2008 , 4(11):e1000228.
39. Wang CY, Mayo MW, Korneluk RG, Goeddel DV, Baldwin AS Jr: NF-kappaB antiapoptosis: induction of TRAF1 and TRAF2 and c-IAP1 and c-IAP2 to suppress caspase-8 activation. Science 1998, 281(5383):1680-1683.

40. Zou T, Rao JN, Guo X, Liu L, Zhang HM, Strauch ED, Bass BL, Wang JY: NFkappaB-mediated IAP expression induces resistance of intestinal epithelial cells to apoptosis after polyamine depletion. Am J Physiol Cell Physiol 2004, 286(5):C1009-1018.

41. Girardin SE, Boneca IG, Viala J, Chamaillard M, Labigne A, Thomas G, Philpott DJ, Sansonetti PJ: Nod2 is a general sensor of peptidoglycan through muramyl dipeptide (MDP) detection. J Biol Chem 2003, 278(11):8869-8872.

42. Ogura Y, Inohara N, Benito A, Chen FF, Yamaoka S, Nunez G: Nod2, a Nod1/Apaf-1 family member that is restricted to monocytes and activates NF-kappaB. J Biol Chem 2001, 276(7):4812-4818.

43. Hsu YM, Zhang Y, You Y, Wang D, Li H, Duramad O, Qin XF, Dong C, Lin X: The adaptor protein CARD9 is required for innate immune responses to intracellular pathogens. Nat Immunol 2007, 8(2):198-205.

44. Ogawa M, Yoshimori T, Suzuki T, Sagara H, Mizushima N, Sasakawa C Escape of intracellular Shigella from autophagy. Science 2005, 307(5710):727-731

45. Gozuacik D, Kimchi A: Autophagy as a cell death and tumor suppressor mechanism. Oncogene 2004, 23(16):2891-2906.

46. Nishina $H$, Sato H, Suzuki T, Sato M, Iba H: Isolation and characterization of fra-2, an additional member of the fos gene family. Proc Natl Acad Sci USA 1990, 87(9):3619-3623.

47. Kantola AK, Keski-Oja J, Koli K: Induction of human LTBP-3 promoter activity by TGF-beta 1 is mediated by $\operatorname{Smad} 3 / 4$ and AP- 1 binding elements. Gene 2005, 363:142-150.

48. Jakowlew SB: Transforming growth factor-beta in cancer and metastasis. Cancer Metastasis Rev 2006, 25(3):435-457.

49. Kiernan R, Bres V, Ng RW, Coudart MP, El Messaoudi S, Sardet C, Jin DY, Emiliani S, Benkirane M: Post-activation turn-off of NF-kappa Bdependent transcription is regulated by acetylation of p65. $\mathrm{J}$ Biol Chem 2003, 278(4):2758-2766

50. Liu ZG, Hsu H, Goeddel DV, Karin M: Dissection of TNF receptor 1 effector functions: JNK activation is not linked to apoptosis while NF-kappaB activation prevents cell death. Cell 1996, 87(3):565-576.

51. Wu MX, Ao Z, Prasad KV, Wu R, Schlossman SF: IEX-1L, an apoptosis inhibitor involved in NF-kappaB-mediated cell survival. Science 1998, 281(5379):998-1001.

52. Martinon F, Burns K, Tschopp J: The inflammasome: a molecular platform triggering activation of inflammatory caspases and processing of prolL-beta. Mol Cell 2002, 10(2):417-426.

53. Bruey JM, Bruey-Sedano N, Luciano F, Zhai D, Balpai R, Xu C, Kress CL, Bailly-Maitre B, Li X, Osterman A, et al:: $\mathrm{BCl}-2$ and $\mathrm{BCl}-\mathrm{XL}$ regulate proinflammatory caspase-1 activation by interaction with NALP1. Cell 2007, 129(1):45-56

54. Headon DJ, Emmal SA, Ferguson BM, Tucker AS, Justice MJ, Sharpe PT, Zonana J, Overbeek PA: Gene defect in ectodermal dysplasia implicates a death domain adapter in development. Nature 2001, 414(6866):913-916.

55. Yan M, Zhang Z, Brady JR, Schilbach S, Fairbrother WJ, Dixit VM: Identification of a novel death domain-containing adaptor molecule for ectodysplasin-A receptor that is mutated in crinkled mice. Curr Biol 2002, 12(5):409-413.

56. Mihara M, Erster S, Zaika A, Petrenko O, Chittenden T, Pancoska P, Moll UM: p53 has a direct apoptogenic role at the mitochondria. Mol Cell 2003, 11(3):577-590.

57. Pietsch EC, Sykes SM, MCMahon SB, Murphy ME: The p53 family and programmed cell death. Oncogene 2008, 27(50):6507-6521.

58. Samuels-Lev Y, O'Connor DJ, Bergamaschi D, Trigiante G, Hsieh JK, Zhong S, Campargue I, Naumovski L, Crook T, Lu X: ASPP proteins specifically stimulate the apoptotic function of p53. Mol Cell 2001, 8(4):781-794

59. Ofek P, Ben-Meir D, Kariv-Inbal Z, Oren M, Lavi S: Cell cycle regulation and p53 activation by protein phosphatase 2 C alpha. J Biol Chem 2003, 278(16):14299-14305.

60. Matsuda K, Yoshida K, Taya Y, Nakamura K, Nakamura Y, Arakawa H: p53AIP1 regulates the mitochondrial apoptotic pathway. Cancer Res 2002, 62(10):2883-2889.

61. Das M, Jiang F, Sluss HK, Zhang C, Shokat KM, Flavell RA, Davis RJ: Suppression of p53-dependent senescence by the JNK signal 
transduction pathway. Proc Natl Acad Sci USA 2007, 104(40):15759-15764

62. Nag A, Bagchi S, Raychaudhuri P: Cul4A physically associates with MDM2 and participates in the proteolysis of p53. Cancer Res 2004 64(22):8152-8155.

63. Abida WM, Nikolaev A, Zhao W, Zhang W, Gu W: FBXO11 promotes the Neddylation of p53 and inhibits its transcriptional activity. J Biol Chem 2007, 282(3):1797-1804

64. Lamb JA, Ventura JJ, Hess P, Flavell RA, Davis RJ: JunD mediates survival signaling by the JNK signal transduction pathway. Mol Cell 2003, 11(6):1479-1489.

65. Carrier F, Georgel PT, Pourquier P, Blake M, Kontny HU, Antinore MJ, Gariboldi M, Myers TG, Weinstein JN, Pommier Y, et al.: Gadd45, a p53responsive stress protein, modifies DNA accessibility on damaged chromatin. Mol Cell Biol 1999, 19(3):1673-1685.

66. Daino K, Ichimura S, Nenoi M: Both the basal transcriptional activity of the GADD45A gene and its enhancement after ionizing irradiation are mediated by AP-1 element. Biochim Biophys Acta 2006, 1759(10):458-469.

67. Woods DB, Vousden KH: Regulation of $\mathrm{p} 53$ function. Exp Cell Res 2001, 264(1):56-66.

68. Witte MM, Scott RE: The proliferation potential protein-related (P2P-R) gene with domains encoding heterogeneous nuclear ribonucleoprotein association and $\mathrm{Rb} 1$ binding shows repressed expression during terminal differentiation. Proc Natl Acad Sci USA 1997, 94(4):1212-1217.

69. Kong L, Yu XP, Bai XH, Zhang WF, Zhang Y, Zhao WM, Jia JH, Tang W, Zhou $\mathrm{YB}, \mathrm{LiU} \mathrm{CJ}: \mathrm{RbAp} 48$ is a critical mediator controlling the transforming activity of human papillomavirus type 16 in cervical cancer. $\mathrm{J}$ Biol Chem 2007, 282(36):26381-26391.

70. Saijo M, Sakai Y, Kishino T, Niikawa N, Matsuura Y, Morino K, Tamai K, Taya $Y$ : Molecular cloning of a human protein that binds to the retinoblastoma protein and chromosomal mapping. Genomics 1995, 27(3):511-519.

71. Benevolenskaya EV, Murray HL, Branton P, Young RA, Kaelin WG Jr: Binding of $\mathrm{pRB}$ to the PHD protein RBP2 promotes cellular differentiation. Mol Cell 2005, 18(6):623-635.

72. Pugh DJ, Ab E, Faro A, Lutya PT, Hoffmann E, Rees DJ: DWNN, a novel ubiquitin-like domain, implicates RBBP6 in mRNA processing and ubiquitin-like pathways. BMC Struct Biol 2006, 6:1.

73. Tonnetti L, Netzel-Arnett S, Darnell GA, Hayes T, Buzza MS, Anglin IE, Suhrbier A, Antalis TM: SerpinB2 protection of retinoblastoma protein from calpain enhances tumor cell survival. Cancer Res 2008, 68(14):5648-5657.

74. Zheng N, Schulman BA, Song L, Miller JJ, Jeffrey PD, Wang P, Chu C, Koepp DM, Elledge SJ, Pagano M, et al:: Structure of the Cul1-Rbx1-Skp1-F boxSkp2 SCF ubiquitin ligase complex. Nature 2002, 416(6882):703-709

75. Singer JD, Gurian-West M, Clurman B, Roberts JM: Cullin-3 targets cyclin E for ubiquitination and controls $S$ phase in mammalian cells. Genes Dev 1999, 13(18):2375-2387.

76. Chen Y, MCPhie DL, Hirschberg J, Neve RL: The amyloid precursor protein-binding protein APP-BP1 drives the cell cycle through the S-M checkpoint and causes apoptosis in neurons. J Biol Chem 2000, 275(12):8929-8935

77. Chestukhin A, Pfeffer C, Milligan S, DeCaprio JA, Pellman D: Processing, localization, and requirement of human separase for normal anaphase progression. Proc Natl Acad Sci USA 2003, 100(8):4574-4579.

78. Festjens N, van Gurp M, van Loo G, Saelens X, Vandenabeele P: Bcl-2 family members as sentinels of cellular integrity and role of mitochondrial intermembrane space proteins in apoptotic cell death. Acta Haematol 2004, 111(1-2):7-27.

79. Johansson $\mathrm{C}$, Lillig $\mathrm{CH}$, Holmgren A: Human mitochondrial glutaredoxin reduces S-glutathionylated proteins with high affinity accepting electrons from either glutathione or thioredoxin reductase. J Biol Chem 2004, 279(9):7537-7543.

80. Rikhof B, Corn PG, El-Deiry WS: Caspase 10 levels are increased following DNA damage in a p53-dependent manner. Cancer Biol Ther 2003, 2(6):707-712.

81. Filomenko R, Prevotat L, Rebe C, Cortier M, Jeannin JF, Solary E, Bettaieb A: Caspase-10 involvement in cytotoxic drug-induced apoptosis of tumor cells. Oncogene 2006, 25(58):7635-7645.
82. Tang ED, Wang CY, Xiong Y, Guan KL: A role for NF-kappaB essential modifier/lkappaB kinase-gamma (NEMO/IKKgamma) ubiquitination in the activation of the IkappaB kinase complex by tumor necrosis factoralpha. J Biol Chem 2003, 278(39):37297-37305.

83. Semino-Mora C, Doi SQ, Marty A, Simko V, Carlstedt I, Dubois A: Intracellular and interstitial expression of Helicobacter pylori virulence genes in gastric precancerous intestinal metaplasia and adenocarcinoma. J Infect Dis 2003, 187(8):1165-1177.

84. Liu H, Rahman A, Semino-Mora C, Doi SQ, Dubois A: Specific and sensitive detection of H. pylori in biological specimens by real-time RTPCR and in situ hybridization. PLoS One 2008, 3(7):e2689.

85. Faherty CS, Maurelli AT: Staying alive: bacterial inhibition of apoptosis during infection. Trends Microbio/ 2008, 16(4):173-180.

86. Binnicker MJ, Williams RD, Apicella MA: Infection of human urethral epithelium with Neisseria gonorrhoeae elicits an upregulation of host anti-apoptotic factors and protects cells from staurosporine-induced apoptosis. Cell Microbiol 2003, 5(8):549-560

87. Danelishvili L, McGarvey J, Li YJ, Bermudez LE: Mycobacterium tuberculosis infection causes different levels of apoptosis and necrosis in human macrophages and alveolar epithelial cells. Cell Microbiol 2003, 5(9):649-660.

88. Okuda J, Arikawa Y, Takeuchi Y, Mahmoud MM, Suzaki E, Kataoka K, Suzuki T, Okinaka Y, Nakai T: Intracellular replication of Edwardsiella tarda in murine macrophage is dependent on the type III secretion system and induces an up-regulation of anti-apoptotic NF-kappaB target genes protecting the macrophage from staurosporine-induced apoptosis. Microb Pathog 2006, 41(6):226-240

89. Bechelli JR, Rydkina E, Colonne PM, Sahni SK: Rickettsia rickettsii infection protects human microvascular endothelial cells against staurosporineinduced apoptosis by a cIAP(2)-independent mechanism. J Infect Dis 2009, 199(9):1389-1398.

90. Sherlock G, Hernandez-Boussard T, Kasarskis A, Binkley G, Matese JC, Dwight SS, Kaloper M, Weng S, Jin H, Ball CA, et al.: The Stanford Microarray Database. Nucleic Acids Res 2001, 29(1):152-155

91. Weibel ER, Kistler GS, Scherle WF: Practical stereological methods for morphometric cytology. J Cell Biol 1966, 30(1):23-38

doi: 10.1186/1471-2164-11-272

Cite this article as: Faherty et al, Microarray analysis of Shigella flexneriinfected epithelial cells identifies host factors important for apoptosis inhibition BMC Genomics 2010, 11:272

\section{Submit your next manuscript to BioMed Central and take full advantage of:}

- Convenient online submission

- Thorough peer review

- No space constraints or color figure charges

- Immediate publication on acceptance

- Inclusion in PubMed, CAS, Scopus and Google Scholar

- Research which is freely available for redistribution 